\title{
Toward Visual Avatars that Dress You Well and Impact Your Health
}

DOI:

10.1109/MCG.2018.021951629

Document Version

Accepted author manuscript

Link to publication record in Manchester Research Explorer

\section{Citation for published version (APA):}

Cao, M., Li, Y., \& Pan, Z. (2018). Toward Visual Avatars that Dress You Well and Impact Your Health. IEEE Computer Graphics and Applications, 38(2), 22-27. https://doi.org/10.1109/MCG.2018.021951629

\section{Published in:}

IEEE Computer Graphics and Applications

\section{Citing this paper}

Please note that where the full-text provided on Manchester Research Explorer is the Author Accepted Manuscript or Proof version this may differ from the final Published version. If citing, it is advised that you check and use the publisher's definitive version.

\section{General rights}

Copyright and moral rights for the publications made accessible in the Research Explorer are retained by the authors and/or other copyright owners and it is a condition of accessing publications that users recognise and abide by the legal requirements associated with these rights.

\section{Takedown policy}

If you believe that this document breaches copyright please refer to the University of Manchester's Takedown Procedures [http://man.ac.uk/04Y6Bo] or contact uml.scholarlycommunications@manchester.ac.uk providing relevant details, so we can investigate your claim.

\section{OPEN ACCESS}




\section{Fire Technology}

\section{New Approaches to Evaluate the Performance of Firefighter Protective Clothing Materials \\ --Manuscript Draft--}

\begin{tabular}{|c|c|c|}
\hline Manuscript Number: & \multicolumn{2}{|l|}{ FIRE-D-18-00012R3 } \\
\hline Full Title: & \multicolumn{2}{|c|}{$\begin{array}{l}\text { New Approaches to Evaluate the Performance of Firefighter Protective Clothing } \\
\text { Materials }\end{array}$} \\
\hline Article Type: & \multicolumn{2}{|l|}{ Manuscript } \\
\hline Keywords: & \multicolumn{2}{|c|}{ firefighter protective clothing; thermal protection; anti-heat stress; total performance } \\
\hline Corresponding Author: & \multicolumn{2}{|c|}{$\begin{array}{l}\text { Yi Li, PhD } \\
\text { School of Materials, The University of Manchester } \\
\text { Manchester, UNITED KINGDOM }\end{array}$} \\
\hline \multicolumn{3}{|l|}{$\begin{array}{l}\text { Corresponding Author Secondary } \\
\text { Information: }\end{array}$} \\
\hline Corresponding Author's Institution: & \multicolumn{2}{|c|}{ School of Materials, The University of Manchester } \\
\hline \multicolumn{3}{|l|}{$\begin{array}{l}\text { Corresponding Author's Secondary } \\
\text { Institution: }\end{array}$} \\
\hline First Author: & \multicolumn{2}{|l|}{ Lu Jin, Master Degree } \\
\hline \multicolumn{3}{|l|}{ First Author Secondary Information: } \\
\hline \multirow[t]{7}{*}{ Order of Authors: } & \multicolumn{2}{|l|}{ Lu Jin, Master Degree } \\
\hline & \multicolumn{2}{|l|}{ Ming Liang Cao, PhD } \\
\hline & \multicolumn{2}{|l|}{ Winnie Yu, PhD } \\
\hline & \multicolumn{2}{|l|}{ Jun Yan Hu, PhD } \\
\hline & \multicolumn{2}{|l|}{ Kee Jong Yoon, PhD } \\
\hline & \multicolumn{2}{|l|}{ Pyoung Kyu Park, PhD } \\
\hline & \multicolumn{2}{|l|}{ Yi Li, PhD } \\
\hline \multicolumn{3}{|c|}{ Order of Authors Secondary Information: } \\
\hline \multirow[t]{2}{*}{ Funding Information: } & $\begin{array}{l}\text { The EU Horizon } 2020 \text { and The University } \\
\text { of Manchester } \\
\text { (Project Codes 644268- } \\
\text { ETEXWELDH2020- MSCA-RISE-2014 } \\
\text { and AA14512) }\end{array}$ & Professor Yi Li \\
\hline & $\begin{array}{l}\text { The Hong Kong Polytechnic University } \\
\text { (PolyU 152097/14E Project Code: } \\
\text { GYBCX) }\end{array}$ & Professor Yi Li \\
\hline Abstract: & \multicolumn{2}{|c|}{$\begin{array}{l}\text { This paper presents new proposals in the evaluation and determination of the optimum } \\
\text { materials suitable for use in the design and development of firefighter protective } \\
\text { clothing by simultaneously addressing the conflicting factors of thermal protection (heat } \\
\text { transfer index }(\mathrm{HTI} \text { ), radiant heat transfer index (RHTI) and thermal threshold index } \\
(\mathrm{TTI}) \text { ) and anti-heat stress (water vapor resistance }(\mathrm{WVR}) \text { and total heat loss }(\mathrm{THL}) \text { ). } \\
\text { To achieve this, this paper proposes new indices for the materials, two types of "total } \\
\text { performance" indices, which are defined as the sum and the product of the competing } \\
\text { factors of thermal protection and anti-heat stress. The results showed that the } \\
\text { candidate materials of firefighter protective clothing were easily rated when the new } \\
\text { indices were applied. Of five candidate materials viz. A, B, B1, B2 and } \mathrm{C} \text {, the B sample, } \\
\text { with values for } \mathrm{HTI} 24=13.2 \pm 0.2 \mathrm{sec}, \mathrm{RHTI} 24=18.0 \pm 0.8 \mathrm{sec}, \mathrm{TTI}=1132 \pm 33 \mathrm{~J} / \mathrm{m} 2 \text {, } \\
\text { WVR=17.5 } \pm 0.3 \mathrm{~m} 2 \mathrm{~Pa} / \mathrm{W} \text { and THL= } 266.2 \pm 4.1 \mathrm{~W} / \mathrm{m} 2 \text {, was found to exhibit the best total } \\
\text { performance. However, the methods proposed to the scientific community in this paper } \\
\text { have so far been validated on a limited data set only, and will require further validation } \\
\text { by a wider group of researchers and with more samples. Lastly, comments on ISO }\end{array}$} \\
\hline
\end{tabular}


11999-3:2015 were also made for the further improvement and development of technical standards.

Powered by Editorial Manager ${ }^{\circledR}$ and ProduXion Manager ${ }^{\circledR}$ from Aries Systems Corporation 


\section{Point-by-point reply}

\section{Comments:}

Notes from the Editor-in-Chief:

Try to include in the abstract quantitative descriptions of some kind (eg, dimensions, amounts, ranges for inputs) and quantitative findings (eg, frequencies, resulting peaks, time scales).

Reply: We have revised the abstract accordingly. 


\section{New Approaches to Evaluate the Performance of Firefighter Protective}

\section{Clothing Materials}

Lu Jin ${ }^{1}$, Ming Liang $\mathrm{Cao}^{2}$, Winnie $\mathrm{Yu}^{3}$, Jun Yan $\mathrm{Hu}^{3}$, Kee Jong Yoon ${ }^{4}$, Pyoung Kyu Park ${ }^{5}$, Yi Li ${ }^{1,2^{*}}$

${ }^{1}$ Faculty of Engineering and Physical Science, School of Materials, The University of Manchester, Manchester, UK

${ }^{2}$ Guangdong Academy of Research on VR Industry, Foshan University, Guang Dong, China ${ }^{3}$ Institute of Textiles and Clothing, The Hong Kong Polytechnic University, Hong Kong, China

${ }^{4}$ Personal Protective Equipment Center, Dankook University, Yongin-si, Gyeonggi-do, Korea

${ }^{5}$ Technical Research Institute, Sancheong, Yongin-si, Gyeonggi-do, Korea

${ }^{*}$ Corresponding author. Email: henry.yili@ manchester.ac.uk Fax: +44 (0) 1613062676 
New Approaches to Evaluate the Performance of Firefighter Protective Clothing Materials

\begin{abstract}
This paper presents new proposals in the evaluation and determination of the optimum materials suitable for use in the design and development of firefighter protective clothing by simultaneously addressing the conflicting factors of thermal protection (heat transfer index (HTI), radiant heat transfer index (RHTI) and thermal threshold index (TTI)) and anti-heat stress (water vapor resistance (WVR) and total heat loss (THL)). To achieve this, this paper proposes new indices for the materials, two types of "total performance" indices, which are defined as the sum and the product of the competing factors of thermal protection and anti-heat stress. The results showed that the candidate materials of firefighter protective clothing were easily rated when the new indices were applied. Of five candidate materials viz. $\mathrm{A}, \mathrm{B}, \mathrm{B}_{1}, \mathrm{~B}_{2}$ and $\mathrm{C}$, the $\mathrm{B}$ sample, with values for $\mathrm{HTL}_{24}=13.2 \pm 0.2 \mathrm{sec}, \mathrm{RHTI}_{24}=18.0 \pm 0.8 \mathrm{sec}$, TTI $=1132 \pm 33$ $\mathrm{J} / \mathrm{m}^{2}, \mathrm{WVR}=17.5 \pm 0.3 \mathrm{~m}^{2} \mathrm{~Pa} / \mathrm{W}$ and THL$=266.2 \pm 4.1 \mathrm{~W} / \mathrm{m}^{2}$, was found to exhibit the best total performance. However, the methods proposed to the scientific community in this paper have so far been validated on a limited data set only, and will require further validation by a wider group of researchers and with more samples. Lastly, comments on ISO 11999-3:2015 were also made for the further improvement and development of technical standards.
\end{abstract}


Keywords: firefighter protective clothing; thermal protection; anti-heat stress; total performance;

\section{Introduction}

There are two conflicting requirements that need to be addressed when designing and developing protective clothing for firefighters. The clothing must sufficiently block the heat from a fire to protect the firefighter against burning whilst effectively dissipating the metabolic heat generated to the environment to prevent heat stress $[1$, 2]. However, more importantly, both competing requirements should be simultaneously considered when designing and developing protective clothing for firefighters to ensure their health and safety together. To achieve this, this paper proposes new indices that evaluate the performance of firefighter protective clothing more holistically to enable the optimum material to be selected.

The protective clothing for firefighters is their only source for thermal protection in a fire [3]. The purpose of the clothing is to reduce the rate of heat buildup on their skin caused by the firefighters exposure to the intense heat, to give them time to react, and to avoid or to minimize any skin burn injury in critically dangerous situations [4]. Therefore, a firefighter protective clothing requires a high level of heat-insulation for thermal protection. Conversely, this requirement hinders the process of dissipating sufficient metabolic heat to the environment, and may result in an increase in core temperature causing heat-related illnesses such as heat cramps, heat exhaustion, heat stroke, and even death [5-8]. In addition, firefighters' tasks such as fire suppression, 
search and technical rescues work demand a high physical burden and entails a large amount of energy consumption [9]. The energy is partly used in their muscles as external work but mostly liberated as heat accumulated in the body, which causes a big increase in the core temperature [10]. In order to prevent the rise in core temperature, the heart pumps a greater volume of blood to the skin to promote heat loss to the environment, incurring an additional load on the cardiovascular system $[10$, 11]. Consequently, the accumulated effect of highly demanding work and inefficient heat loss may lead to the heart attack which has been identified as the primary cause of fatality for firefighters [11]. Therefore, the two competing requirements viz. the performance of thermal protection (P-TP) and the performance of anti-heat stress (P-AHS) for firefighter protective clothing should be considered together when selecting materials to use in the design and construction of the life-saving protective clothing to minimize the possibility of firefighter fatalities.

Unfortunately, most previous research has focused on either thermal protection or heat stress of firefighter protective clothing without considering two factors together [4, 11-14]. Although some research analyzed both the thermal protection and the physiological burden of firefighter protective clothing, they did not provide the proper way to address two factors at the same time when selecting the optimal material/garment among candidate samples $[15,16]$. This might cause the design failure of firefighter protective clothing. It is an unsolved question frequently encountered by engineers and designers because, for example, it is invariably difficult, in practice, to decide which is the optimal clothing assembly when one assembly 
exhibits a higher P-TP but lower P-AHS than another that exhibits a higher P-AHS but lower P-TP [3, 17]. Ideally, the firefighter protective clothing should provide the highest P-TP and at the same time confer the maximum P-AHS $[3,18]$, but, inherently, these two requirements conflict with each other.

Therefore, this study proposes novel approaches to scientifically evaluate candidate materials for firefighter protective clothing through the use of newly developed, holistic, simple-to-use indices to avoid possible errors at the initial stage of the development of firefighter protective clothing. It is hypothesized that, if the comprehensively measured P-TP and P-AHS are considered simultaneously, this will enable the selection of the optimum materials for the development of the protective clothing for firefighters. Furthermore, the standard of ISO 11999-3:2015 are critically examined through comparing with NFPA 1971:2013 and EN 469:2014, and comments on ISO 11999-3:2015 are made for the further improvement and development of technical standards.

\section{Experimental}

\subsection{Materials}

A firefighter protective clothing assembly typically comprises of three layers of fabrics to provide the desired thermal protection $[3,4]$. They include an outer layer, a moisture barrier, and a thermal barrier. In this study, three kinds of outer layers $\left(\mathrm{O}_{1}\right.$, $\left.\mathrm{O}_{2}, \mathrm{O}_{3}\right)$, two types of moisture barriers $\left(\mathrm{M}_{1}, \mathrm{M}_{2}\right)$ and three sorts of thermal barriers $\left(\mathrm{T}_{1}\right.$, $\mathrm{T}_{2}, \mathrm{~T}_{3}$ ) were employed to construct five different combinations of assemblies (A, B, 
$\left.\mathrm{B}_{1}, \mathrm{~B}_{2}, \mathrm{C}\right)$, taking into consideration both the performance requirements and cost. These are setout in Table 1 . All specimens were conditioned at $20^{\circ} \mathrm{C}$ temperature and $65 \%$ relative humidity for 24 hours, before conducting the standard tests.

\subsection{International standards relating to firefighter protective clothing}

Three international standards regarding firefighter protective clothing viz. ISO 11999-3:2015, NFPA 1971:2013 and EN 469:2014 were compared, as shown in Table 2 [19-21]. This revealed that ISO 11999-3:2015 covers most of the content in NFPA 1971 and EN 469. Therefore, both P-TP and P-AHS of each firefighter protective clothing assembly were measured in accordance with ISO 11999-3:2015.

\subsection{Thermal protection tests}

Three thermal protection tests were conducted as follows.

\subsubsection{Flame protective performance test}

The flame protective performance (FPP) is an important thermal protection indicator required to be tested in both ISO 11999-3:2015 and EN 469:2014. An FPP tester (TPP-2-x, Govmark, USA) made in accordance with ISO 9151, was used to evaluate the FPP of the specimens at a heat flux density of $80 \mathrm{~kW} / \mathrm{m}^{2}[19,21-24]$. The following heat transfer index (HTI) values that define the level of FPP were detected.

- $\mathrm{HTI}_{12}$ : Time to achieve a temperature rise of $12{ }^{\circ} \mathrm{C}$ in the calorimeter of the FPP tester at a specified incident heat flux density-This time is a rough measure of the time before pain experienced; 
- $\mathrm{HTI}_{24}$ : Time to achieve a temperature rise of $24{ }^{\circ} \mathrm{C}$ in the calorimeter of the FPP tester at a specified incident heat flux density-This is roughly equal to the time it takes to suffer a second-degree burn.

- $\mathrm{HTI}_{24}-\mathrm{HTI}_{12}$ : Escape time from feeling pain to suffering a second-degree burn.

\subsubsection{Radiant protective performance test}

Radiant protective performance (RPP) test is also specified in both ISO 11999-3:2015 and EN 469:2014. An RPP tester (HBP DIN EN ISO 6942, Wazau, Germany) consists principally of four parts namely, a source of radiation, a specimen holder, a calorimeter and a temperature recorder according to ISO 6942. The radiant heat transfer index (RHTI) representing the RPP was recorded at a heat flux density of 40 $\mathrm{kW} / \mathrm{m}^{2}$. The values of $\mathrm{RHTI}_{12}, \mathrm{RHTI}_{24}$, and $\mathrm{RHTI}_{24}-\mathrm{RHTI}_{12}$ are defined in the same way as the HTI values [19, 21, 22, 24].

\subsubsection{Thermal protective performance test}

Both ISO 11999-3:2015 and NFPA 1971:2013 specify the thermal protective performance (TPP) test. The thermal flux source consists of a convective thermal-flux source similar to that of an FPP tester, and a radiant thermal-flux source similar to that of an RPP tester [25]. In accordance with ISO 17492, the thermal threshold index (TTI) in a unit of $\mathrm{kJ} / \mathrm{m}^{2}$ was determined at a combined heat flux density of $80 \mathrm{~kW} / \mathrm{m}^{2}$ $[19,20,25]$. The TTI value is calculated using Equation (1).

$T T I=F \times t_{2 B u r n}$

Equation (1) 
where $F$ is the incident heat flux density (unit: $\mathrm{kW} / \mathrm{m}^{2}$ ) and $t_{2 b u r n}$ is the time to get the second-degree burn injury (unit: sec.).

The definition of TPP rating specified in NFPA 1971:2013 is the same as that of TTI, but the unit is different, the TPP rating uses a unit of $\mathrm{cal} / \mathrm{cm}^{2}$.

\subsection{Anti-heat stress tests}

Tests were performed to derive the required P-AHS indices as follows.

\subsubsection{Water vapor resistance and thermal resistance}

Both ISO 11999-3:2015 and EN 469:2014 specify the minimum requirement for the water vapor resistance (WVR, $\mathrm{m}^{2} \mathrm{~Pa} / \mathrm{W}$ ) value which is a crucial indicator of $\mathrm{P}$-AHS of firefighter protective clothing. In this study, the fabric tests were conducted in accordance with ISO 11092 . The temperature of the testing environment was $35^{\circ} \mathrm{C}$ as the hot plate and the relative humidity was $40 \%[19,21,26]$. The WVR is the difference in the water vapor partial pressures between the two sides of a specimen divided by the evaporative heat flux per unit area, as shown in Equation (2):

$W V R=\frac{\left(P_{\text {surf }}-P_{a m b}\right) \times A}{H}$ Equation (2) where $P_{\text {surf }}$ is the water vapor partial pressure at the surface of the hot plate (unit: $\mathrm{Pa}$ ), $P_{a m b}$ is water vapor partial pressure in ambient air (unit: $\mathrm{Pa}$ ), $A$ is the area of the hot plate (unit: $\mathrm{m}^{2}$ ) and $H$ is the supplied heating power (unit: W).

In addition, the thermal resistance $\left(\mathrm{TR}, \mathrm{m}^{2} \mathrm{~K} / \mathrm{W}\right)$ of each specimen was tested at $20{ }^{\circ} \mathrm{C}$ temperature and $65 \%$ relative humidity and determined using Equation (3):

$T R=\frac{\left(T_{\text {surf }}-T_{a m b}\right) \times A}{H}$ Equation (3) 
where $T_{\text {surf }}$ is the temperature (unit: $\mathrm{K}$ ) of the hot plate, $T_{a m b}$ is ambient temperature (unit: $\mathrm{K}$ ), $A$ is the area (unit: $\mathrm{m}^{2}$ ) of the hot plate and $H$ is the supplied heating power (unit: W).

\subsubsection{Total heat loss}

Total heat loss (THL, unit: $\mathrm{W} / \mathrm{m}^{2}$ ) as required in both ISO 11999-3:2015 and NFPA 1971:2013, was calculated by a summation of the heat loss $\left(Q_{h}\right)$ and the evaporation loss $\left(Q_{e}\right)$ using Equation (4) as defined in ASTM F 1868 part C [19, 20, 27].

$T H L=Q_{h}+Q_{e}=\frac{m}{T R+0.04}+\frac{n}{W V R / 1000+0.0035}$ Equation (4) where $m$ is the temperature gradient $10{ }^{\circ} \mathrm{C}$ and $n$ is pressure difference $3.57 \mathrm{kPa}$.

\section{Results}

\subsection{Thermal protection}

\subsubsection{Flame protective performance}

Table 3 shows the results of the FPP for each specimen. According to ISO 11999-3:2015 in Table 2 [19], as both the A and B samples exhibited an $\mathrm{HTI}_{24}$ value higher than $13 \mathrm{~s}$, their performance level was regarded as $\mathrm{A} 1$, the other samples exhibited $\mathrm{HTI}_{24}$ values exceeding $17 \mathrm{~s}$, so these were deemed to have a higher performance level of $\mathrm{A} 2$. Of course, the escape time $\left(\mathrm{HTI}_{24}-\mathrm{HTI}_{12}\right)$ increases with $\mathrm{HTI}_{24}$. The time to get a second-degree burn ( $\left.\mathrm{t}_{2 \mathrm{Burn}}\right)$ of each assembly was also determined using the FPP tester and compared with the $\mathrm{HTI}_{24}$ value. It reveals that the

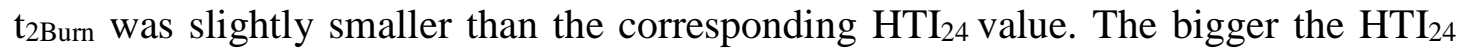


value, the smaller the difference was. This is attributed to the fact that the Stoll Curve, which quantifies the heat level and the time duration needed for a second-degree burn for a wide range of exposure conditions [28], converges on the $\mathrm{T}_{24}$ line, which is used for determining the $\mathrm{HTI}_{24}$ value, when the exposure time increases, as shown in Figure 1. This result also reveals that the $\mathrm{HTI}_{24}$ value was approximately equal to the $\mathrm{t}_{2 \mathrm{Burn}}$ value.

\subsubsection{Radiant protective performance}

As listed in Table 4, according to ISO 11999-3:2015 [19], the RHTI 24 value of the B sample just met the performance level $\mathrm{A} 1$, the $\mathrm{B}_{1}, \mathrm{~B}_{2}$ and $\mathrm{C}$ samples achieved the higher performance level A2, but the A sample failed the RPP test. In the FPP test, the heat transfers from a fire source to the specimen, so it involves convection, conduction, and radiation, while radiation is the only means of heat transfer in the RPP test. In fact, the firefighters are subjected to considerable heat by radiation during firefighting [3]. One of the effective ways to protect them from radiant heat is to improve the reflectance of the outer protective layer using aluminized fabrics or similar, to reflect the radiant heat [22]. This phenomenon was also observed in this study. Despite the identical thickness and similar combination of materials, the B sample showed a significantly higher $\operatorname{RHTI}_{24}$ value than A sample $(p<0.01)$. This was mainly ascribed to the difference in the reflectance of the outer layers between these two assemblies. Obviously, because A sample is black color, it had a lower reflectance, resulting in absorbing more radiant heat at the beginning of exposure. It is 
noticeable that although the radiant heat flux density utilized in the RPP test is only half of that used in FPP test, the $\mathrm{RHTI}_{24}$ value of A was equal to its $\mathrm{HTI}_{24}$ value. One main reason is that the radiant heat can permeate into the fabric to a certain depth, leading to more serious damage even at a low-level radiant heat $[29,30]$. Therefore the outer layer plays an important role in the radiant heat protection [22]. Presumably, this is one of the reasons why NFPA 1971:2013 requires only the garment's outer shell material to be tested in the RPP test in accordance with ASTM F1939 [20].

\subsubsection{Thermal protective performance}

Table 5 shows the thermal protective performance (TPP) of each specimen in terms of TTI, TPP, and $\mathrm{t}_{2 \mathrm{Brun}}$. The TTI values of both A and B samples achieved a performance level of A1, and the others were at a higher level of A2 according to ISO 11999-3:2015 [19]. Although the $t_{2 B u r n}$ in the TPP test was slightly higher than that in the FPP test (Table 3) due to different heat sources and exposed areas, the overall trend of the results from both tests is similar as shown in Figure 2. Moreover, it should be noted that the A sample was damaged after the TPP test while in the FPP test it had maintained its integrity, except that the exposed area became swollen as shown in Figure 3. All other samples retained their integrity well after both TPP and FPP test. It is important for the outer layer materials to be thermally stable at a high temperature. If the outer layer loses its integrity, it cannot provide enough protection from fire [3, 4]. Moreover, the proportion of the radiant heat element within the source of the TPP tester accounts for $50 \%$ of the total heat flux, and, thus, the 
performance of the specimen is measured under realistic conditions closer to the exposure intensity than that of the FPP tester $[17,22,25]$. Therefore, the TPP test could offer more comprehensive information than that FPP test provides. However, the TPP test cannot be used as an alternative to the RPP test, due to the fact that once the fire contacts with the surface of the outer layer, it blackens the surface and can significantly affect the surface reflectance as shown in Figure 3. Therefore, the sentence "As an alternative to meeting the requirements of 4.16 .4 and 4.16 .5 " in ISO 11999-3:2015 needs to be corrected [19].

\subsection{Anti-heat stress}

\subsubsection{Water vapor resistance and thermal resistance}

WVR is an important parameter that is associated with P-AHS of a garment, because a high WVR can lead to the moisture created by sweating staying inside the clothing system resulting in a sensation of wet clinginess and thermal discomfort to the wearer [3]. The WVR and TR of each specimen were measured in accordance with ISO 11092 using a sweating guarded hotplate device and the values listed in Table 6. Both ISO 11999-3:2015 and EN 469:2014 specify the WVR value to assess the P-AHS [19, 21, 26]. According to ISO 11999-3:2015, the WVR values of all specimens achieved the requirement of the performance level $\mathrm{d}_{2}$ which is less than $30 \mathrm{~m}^{2} \mathrm{~Pa} / \mathrm{W}$ [19].

\subsubsection{Total heat loss}

The THL value of each specimen was calculated in accordance with Equation (3) in 
ASTM F 1868 part C and listed in Table 6 [27]. It is notable that although the WVR values of all specimens were at the performance level $\mathrm{d}_{2}$, when it comes to THL, no tested specimen satisfied the requirement of performance level $\mathrm{d}_{2}$ specified in ISO 11999-3:2015 [19]. Only the A and B samples, which had THL values greater than $200 \mathrm{~W} / \mathrm{m}^{2}$, fulfilled the performance level $\mathrm{d}_{1}$ as shown in Table 6 . Not only our study but this inconsistency of performance level could also be observed in a previous study. Song G. et al.[31] measured WVR and TR of ten assemblies and calculated THL from WVR and TR and listed in Table 8 in their paper, showing that WVR for seven samples satisfied the requirement of performance level $\mathrm{d}_{2}$ specified in ISO 11999-3, but their THL values even cannot fulfill the level $d_{1}$.

ISO 11999-3:2015 states that both the WVR and THL can be used to assess the ability to transfer heat allowed by the specimen and the two methods for determining them are intended to provide comparable results, however, there is still a slightly difference between them. The measurement of WVR is related to heat dissipated only by evaporation because of the isothermal test environment (i. e. there is no difference in temperature between the skin and the air), while the measurement of THL indicates the heat lost by both evaporation and conduction since it denote the heat transferred at a $10{ }^{\circ} \mathrm{C}$ temperature gradient between the air and the skin's surface [19]. This difference may have caused the discordance results in between WVR and THL values measured in this study. Even if such discordance only happens rarely, the results of five specimens used in this study are strong evidences. Therefore, the performance level of anti-heat stress specified in ISO 11999-3:2015 requires further examination. 


\section{Discussion}

\subsection{Relationship between both performance of thermal protection and anti-heat stress of firefighter protective clothing}

According to the results of thermal protection test (choosing $\mathrm{HTI}_{24}$ values from FPP test) and anti-heat stress test (choosing THL values), the five different fabric specimens can be classified into three groups:

i. $\mathrm{A}$ and $\mathrm{B}\left(\mathrm{HTI}_{24} \approx 14 \mathrm{sec}\right.$. and $\left.\mathrm{THL} \approx 270 \mathrm{~W} / \mathrm{m}^{2}\right)$

ii. $\mathrm{B}_{1}$ and $\mathrm{C}\left(\mathrm{HTI}_{24} \approx 23 \mathrm{sec}\right.$. and $\left.\mathrm{THL} \approx 190 \mathrm{~W} / \mathrm{m}^{2}\right)$

iii. $\mathrm{B}_{2}\left(\mathrm{HTI}_{24} \approx 27.5 \mathrm{sec}\right.$. and $\left.\mathrm{THL} \approx 164 \mathrm{~W} / \mathrm{m}^{2}\right)$

Comparing above three groups, it is clear that the better the P-TP, the worse the P-AHS is, indicating that P-TP and P-AHS are conflicting factors. The underlying mechanism for this phenomenon can be readily explained by the ways of heat exchange within the processes of thermal protection and heat stress. Dry-heat transfers such as conduction, radiation and convection occur in both processes of thermal protection and heat stress while their directions are opposite as shown in Figure 4, resulting in P-TP and P-AHS are conflicted with each other. However, unlike the process of thermal protection that is mainly dominated by dry-heat transfer, there are extra avenues of heat transfer such as sweat vapor transfer and heat transfer by ventilation (pumping effect) occurring in the process of heat stress. Especially, in case of fighting fire, the moist-heat transfer is the only way to dissipate body heat since the environment temperature is higher than body temperature [1]. Moreover, 
metabolic heat could also be exchanged with the environment along with the air gap (microclimate) to promote the sweat vapor transfer, in which the direction is perpendicular to that of the dry-heat transfer $[14,32]$. P-TP of firefighter protective clothing could be, therefore, determined by clothing thickness, precisely trapped air within fabric, as well as air gap size between skin and clothing [33, 34], but except for these, P-AHS could also be affected by garment design, fit, fabric structure and fiber's chemical properties such as hydrophilicity [14]. In addition to that, one feature for thermal protection is that the process occurs rapidly, within several seconds, under high intense heat exposure. In contrast, heat stress is a much slower and more complicated process than that of thermal protection [35].

In summary, this clearly indicates that the processes of thermal protection and heat stress can be independent of each other to a certain degree, because it is, technically, possible to improve independently P-AHS of firefighter protective clothing material through optimizing the fabric structure and fiber properties to maximize sweat vapor transfer or by utilizing advanced materials such as self-cooling materials (ferroelectric materials), shape-memory alloys and so forth $[36,37]$.

\subsection{Selection of the optimum firefighter protective clothing material}

Then there is a scientific question frequently encountered by designers and engineers when developing a new firefighter protective clothing - if three representative specimens, which are $\mathrm{B}, \mathrm{B}_{1}$ and $\mathrm{B}_{2}$, are selected from each aforementioned group, these three specimens meet all the minimum requirements of P-TP and P-AHS as 
specified in ISO 11999-3:2015. Yet it is difficult to decide which is the best assembly overall for making a firefighter protective clothing since, ideally, the firefighter protective clothing should provide both the highest P-TP and the maximum P-AHS at the same time $[3,18]$. To solve this problem, new indices, which simultaneously reflect conflicting P-TP and P-AHS indices of firefighter protective clothing material, are proposed and analyzed in this study.

\subsubsection{Selecting indices for P-TP and P-AHS}

Before devising new indices, suitable indices we examined in this study were selected for P-TP and P-AHS. Regarding P-TP indices, the time to get a second-degree burn injury ( $\left.\mathrm{t}_{2 \mathrm{Burn}}\right)$ is a critical factor because the injury beyond second-degree burn is not recoverable. We obtained $\mathrm{t}_{2 \mathrm{Burn}}$ values from FPP test and TPP test, respectively. Although, they had comparable results as shown in Figure 2, the $t_{2 B u r n}$ values obtained from TPP test were chosen since TPP test are much more reliable than FPP test as discussed in 3.1.3 Thermal protective performance. Moreover, to reduce the error caused by calibration process in TPP test, TTI indices were selected. When it comes to P-AHS indices, WVR and THL specified in ISO 11999-3:2015, THL has been identified as one of key parameters related to the P-AHS of firefighter protective clothing $[19,20,26]$. Nevertheless, THL index could be difficult to determine the realistic P-AHS of the firefighter protective clothing made from five assemblies tested. This is because heat stress is very complex sensing process and determined by the human thermoregulatory system's (metabolic rate, core temperature, heart rate, 
perspiration, respiration) interactions with the clothing characteristics (design, chemical properties, weight, thickness) and external environment (temperature, vapor pressure, air speed, radiation) [38]. Therefore, we included the weight and thickness of each assembly, recognized as two key factors of firefighter protective clothing material, in the calculation of P-AHS of firefighter protective clothing material to partially compensate the defect of THL. Studies have shown that the weight and thickness of a firefighter protective clothing have a negative effect on its P-AHS because both increase the physical exertion required and hinder the mobility of firefighters, aggravating the metabolic rate $[3,5,6,35,39-41]$. Hence P-TP and P-AHS are expressed as follows:

$P-T P=$ Thermal threshold index $(T T I)$

Equation (5)

$P-A H S=\frac{\text { Total heat loss }(T H L)}{\delta \times w}$ Equation (6)

Where $\delta$ is the thickness of specimen $(\mathrm{mm}), w$ is weight per unit area $\left(\mathrm{g} / \mathrm{m}^{2}\right)$.

\subsubsection{Sum of P-TP and P-AHS}

Then the next step is to integrate TTI (P-TP index) and $\frac{\mathrm{THL}}{\delta \times \mathrm{w}}$ (P-AHS index). One possible solution is to do the sum of TTI and $\frac{T H L}{\delta \times w}$ to create a new index. However, a problem is that TTI and $\frac{\mathrm{THL}}{\delta \times \mathrm{w}}$ are different physical factors, having different scales (TTI values $>10^{3}$ but $\frac{\mathrm{THL}}{\delta \times \mathrm{w}}$ values $<1$ as shown in Table 7) and units, and are considered as independent of each other. In order to plus two indices at the same scale, first, we normalized these two indices through min-max normalization method. Min-max normalization is a data processing technique widely used in various 
disciplines. This method rescales the features from one range of values to a new range of values, from zero to one [42]. One benefit for min-max normalization method is that it preserves exactly all relationships in the data, thus the ranking (performance level) of each specimen tested will not be changed after normalization [43]. The rescaling of TTI and $\frac{\mathrm{THL}}{\delta \times \mathrm{w}}$ is performed by using a linear interpretation formula, Equation (7), the results are setout in Table 7.

$X_{\text {norm }}=\frac{X_{i}-X_{\min }}{X_{\max }-X_{\min }}$ Equation (7)

Where $X_{i}$ is the initial value of TTI or $\frac{\text { THL }}{\delta \times w}, \quad X_{n o r m}$ is the normalized value, $X_{\max }$ is the maximum value within TTI or $\frac{\mathrm{THL}}{\delta \times \mathrm{w}}$ values and $X_{\min }$ is the minimum value within TTI or $\frac{\mathrm{THL}}{\delta \times \mathrm{w}}$ values.

If so, it is difficult to explain the physical meaning of this new index after normalization. Therefore, we newly define this index as "Total Performance" (TP) of firefighter protective clothing. Hence, the $\mathrm{TP}_{\text {sum }}$ can be derived using Equation (8).

$T P_{\text {sum }}=\alpha \times(T T I)_{n}+\beta \times\left(\frac{T H L}{\delta \times w}\right)_{n}$

Equation (8)

Where $\alpha$ and $\beta$ are weighting values, $(T T I)_{n}$ is the normalized TTI value and $\left(\frac{T H L}{\delta \times w}\right)_{n}$ is the normalized $\frac{T H L}{\delta \times w}$ value.

We also introduced weighting values in Equation (8), $\alpha$ and $\beta$, which could be determined on the basis of the different situations and requirements [44]. This is because not only simultaneously addressing both factors, P-TP and P-AHS, is critical, but also considering the weights (probabilities) of both factors in real situations when designing and developing protective clothing for firefighters is essential. For instance, $\alpha$ and $\beta$ could be allocated based on the probability of working duties. 
Indeed, firefighters spend only a small percentage of time on firefighting [3, 17]; about $95 \%$ of their tasks are technical rescue work that often has a relatively low level of danger and heat exposure. Even so, they have to wear a firefighter protective clothing, indicating that the P-AHS of firefighter protective clothing would be much more important than the P-TP. In this case, $\alpha$ and $\beta$ can be allocated into 0.05 and 0.95, respectively. Moreover, $\alpha$ and $\beta$ could be allocated according to the probability of the causes of firefighter fatality. For instance, the death number of firefighters from burn injury was 4 in 2015 in the United State, but the deaths due to heat stress/heart attack were 54 [45], thereby $\alpha$ and $\beta$ can be allocated into 0.07 and 0.93, respectively. Figure 5 displays the $\mathrm{TP}_{\text {sum }}$ values for firefighter protective clothing assemblies at diverse weighting values, showing that the samples are clearly sorted. Obviously, the higher the $\mathrm{TP}_{\text {sum }}$ value, the better the whole performance is at a fixed weighting value. However, one thing should be noted, according to Figure 5,

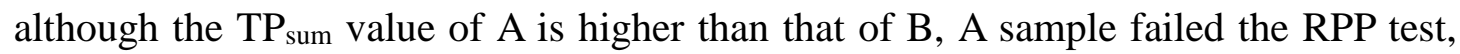
hence the $\mathrm{B}$ would be the best option when $\alpha$ and $\beta$ are 0.07 and 0.93 , respectively.

\subsubsection{Product of P-TP and P-AHS}

Another feasible avenue is to do the product of TTI (P-TP index) and $\frac{\text { THL }}{\delta \times w}$ (P-AHS index) to be used as a new total performance index. Hence, $\mathrm{TP}_{\text {product }}$ can be simply derived using Equation (9).

$T P_{\text {product }}=T T I \times\left(\frac{T H L}{\delta \times w}\right)$ Equation (9)

This approach originates from the following concept. Normally an enhanced P-TP 
of firefighter protective clothing may be achieved at the expense of P-AHS and vice versa because they are competing factors. The research question is to what extent P-AHS is sacrificed to achieve the enhanced P-TP. The advantage of in using the product of $\mathrm{P}-\mathrm{TP}$ and $\mathrm{P}$-AHS as a new index is that the loss or gain in total performance of firefighter protective clothing can be easily calculated. For instance, there are two new design strategies that need to be compared with a reference firefighter protective clothing material, and one design strategy can improve the P-TP to $110 \%$ but decreases the P-AHS to $70 \%$; while the other one can enhance the P-AHS to $120 \%$ but only reduce the P-TP to $95 \%$ compared to the reference sample. Then their gain and loss in total performance can be readily calculated according to Equation (9):

Former design: $\mathrm{TTI}_{\text {ref }}(110 \%) \times \frac{\mathrm{THL}}{\delta \times \mathrm{w}} \mathrm{ref}(70 \%)=\mathrm{TP}_{\text {product.ref }}(77 \%)$

Latter design: $\mathrm{TTI}_{\text {ref }}(95 \%) \times \frac{\mathrm{THL}}{\delta \times \mathrm{w}}$ ref $(120 \%)=\mathrm{TP}_{\text {product.ref }}(114 \%)$

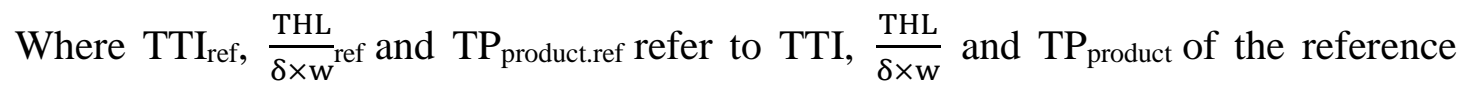
sample, respectively.

From these calculations, the former design strategy loses $23 \%$, while the latter one gains $14 \%$ in total performance compared to the reference one, indicating that the latter design strategy is better option. In the same way, this method can be applied to aforementioned question selecting the best sample among $\mathrm{B}, \mathrm{B}_{1}$ and $\mathrm{B}_{2}$ through designating one sample as a reference.

However, there is a much easier way to achieve this. In order to further illuminate

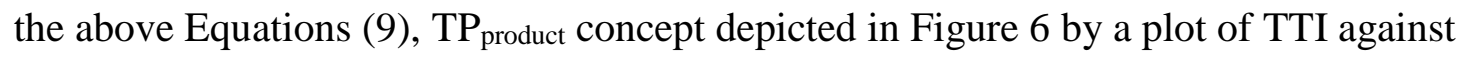


$\frac{T H L}{\delta \times w}$ for five specimens, thereby the rectangles depicted by TTI and $\frac{T H L}{\delta \times w}$ as shown in Figure 6 can be used as the new index of $\mathrm{TP}_{\text {product }}$ for each specimen. This helps the selection of the best specimen by just simply comparing the area of rectangular $\left(\mathrm{TP}_{\text {product }}\right)$ instead of the separate and conflicting values of TTI or $\frac{\mathrm{THL}}{\delta \times \mathrm{w}}$. Figure 7 shows the area of rectangular $\left(\mathrm{TP}_{\text {product }}\right)$ of each sample, certainly, the larger area, the better total performance is. Similarly, except for A sample which failed the RPP test, the second biggest area, B sample, is the best option among the five specimens as shown in Figure 7.

\subsection{Comparison and analysis of two total performance indices}

Compared with $\mathrm{TP}_{\text {product }}$ index, $\mathrm{TP}_{\text {sum }}$ index seems to be much more flexible because of the weighting values, $\alpha$ and $\beta$, in Equation (8), which could also be decided by designers and end-users such as firefighters according to their performance requirements on firefighter protective clothing. On the other hand, $\mathrm{TP}_{\text {sum }}$ index is suitable for the large sample population since the accuracy of $\mathrm{TP}_{\text {sum }}$ index would increase with the number of samples raise. In contrast, the sensitivity of $\mathrm{TP}_{\text {product }}$ index would be much higher than that of $\mathrm{TP}_{\text {sum }}$ index since $\mathrm{TP}_{\text {product }}$ is the product of $\mathrm{P}-\mathrm{TP}$ and $\mathrm{P}$-AHS. Moreover, it is much easier for $\mathrm{TP}_{\text {product }}$ index to be calculated since there is no normalization process. We also cross-checked $\mathrm{TP}_{\text {sum }}$ with $\mathrm{TP}_{\text {product }}$, because the two new indexing system are originated from different concepts and the calculation processes are very dissimilar. Figure 8 shows that $\mathrm{TP}_{\text {sum }}(\alpha=0.07$ and $\beta=0.93)$ is highly linearly correlated with $\mathrm{TP}_{\text {product }}$ and their correlation coefficient is 0.98 , which 
reaffirms that $\mathrm{TP}_{\text {product }}$ is feasible as an alternative to $\mathrm{TP}_{\text {sum }}$ and vice versa.

\subsection{Advantages and limitations of two total performance indices}

Technically, the new indices, $\mathrm{TP}_{\text {sum }}$ and $\mathrm{TP}_{\text {product }}$, can be used for the optimal design of a firefighter's protective clothing assembly. In this study, disregarding the A sample because of its loss of integrity in the TPP test and failed in RPP test, the B sample was better because it showed higher $\mathrm{TP}_{\text {sum }}$ and $\mathrm{TP}_{\text {product }}$ values than the $\mathrm{B}_{1}$ and $\mathrm{B}_{2}$ samples. This may prompt a design strategy to increase the thickness and weight of $\mathrm{B}_{1}$ and $\mathrm{B}_{2}$ to make them a better thermal protection is in turn counterproductive. This is because, as seen from the Equations (6), P-AHS is restricted by both its weigh and thickness, which are considered as two influential factors in the design and development of firefighter protective clothing. The $\mathrm{TP}_{\text {sum }}$ and $\mathrm{TP}_{\text {product }}$ indices are, therefore, good indicators for the optimal design of firefighter protective clothing to help engineers avoid design mistake through "unbiased design". By constantly increasing the TP of the specimen based on the developed equations, the optimal design can be achieved.

Nevertheless, it should be noted that two TP indices are entirely subordinate to all indices specified in ISO 11999-3:2015. This is because, for instance, if a specimen cannot satisfy one of the minimal requirements for clothing materials, design and performance specifications in ISO 11999-3:2015, it should be excluded no matter how high the values of TP are for the specimen, like A sample. Another limitation for TP indices are that, although introducing the two key factors, thickness and weight of firefighter protective clothing material, in calculation of P-AHS to compensate the drawback of THL, it still could not correctly reflect the real performance of firefighter 
protective clothing. For instance, THL test could not consider the heat diffusion by ventilating along with air gap, pumping effect in other word. The new TP indices proposed in this study would be, therefore, only suitable for comparing the assembly of firefighter protective clothing.

\section{Conclusion}

In this study, two types of $\mathrm{TP}$ indices, $\mathrm{TP}_{\text {sum }}$ and $\mathrm{TP}_{\text {product }}$, have been proposed and applied to five candidate materials as example cases to show how the new indices work. The results showed that the new TP indices could provide effective and practical ways to holistically evaluate the candidate materials and readily select the best material for the optimal design of firefighter protective clothing by simultaneously considering the conflicting factors of P-TP and P-AHS. However, additional study is needed with more candidate materials to evaluate the usefulness of the new indexing system proposed in this study.

In addition, two comments for ISO 11999-3:2015 have emerged from this study. First, the TPP test should not be considered as an alternative to the RPP test because the flame used in the TPP test will blacken the surface and significantly affect the surface reflectance. Second, the performance levels of WVR and THL specified in the ISO 11999-3:2015 requires further examination because the discordance has happened in between WVR and THL level in this study. The approaches and concepts introduced in this study could also be applied to other personal protective equipment used by firefighters such as fire hoods, footwear and gloves and so forth, as well as to 
other protective clothing systems.

\section{Acknowledgments}

We would like to thank The Hong Kong Polytechnic University for funding the research through the project entitled "Personal Protection against Burn Injury and Heat Stress for Firefighters" (PolyU 152097/14E Project Code: G-YBCX). Also, we would like to thank the support of the EU Horizon 2020 and The University of Manchester through projects with Project Codes 644268-ETEXWELD-H2020-MSCA -RISE-2014 and AA14512. We thank Dr. Simon Harlock for his professional editing.

\section{References}

1. Rossi R (2003) Fire fighting and its influence on the body. Ergonomics 46:1017-1033 . doi: 10.1080/0014013031000121968

2. Eglin CM (2007) Physiological Responses to Fire-fighting: thermal and Metabolic Considerations. J Human-Environment Syst 10:7-18

3. Nayak R, Houshyar S, Padhye R (2014) Recent trends and future scope in the protection and comfort of fire-fighters' personal protective clothing. Fire Sci Rev 3:4 . doi: 10.1186/s40038-014-0004-0

4. Jin L, Hong K, Yoon K (2013) Effect of Aerogel on Thermal Protective Performance of Firefighter Clothing Experimental Materials. J Fiber Bioeng Informatics 3:315-324 . doi: 10.3993/jfbi09201309

5. Holmér I, Kuklane K, Gao C (2006) Test of firefighter's turnout gear in hot and 
humid air exposure. Int J Occup Saf Ergon 12:297-305 . doi:

$10.1080 / 10803548.2006 .11076689$

6. Dorman LE, Havenith G (2009) The effects of protective clothing on energy consumption during different activities. Eur J Appl Physiol 105:463-70 . doi: $10.1007 / \mathrm{s} 00421-008-0924-2$

7. Bröde P, Kuklane K, Candas V, et al (2010) Heat gain from thermal radiation through protective clothing with different insulation, reflectivity and vapour permeability. Int J Occup Saf Ergon 16:231-44

8. Miller VS, Bates GP (2007) The thermal work limit is a simple reliable heat index for the protection of workers in thermally stressful environments. Ann Occup Hyg 51:553-61 . doi: 10.1093/annhyg/mem035

9. Barr D, Gregson W, Reilly T (2010) The thermal ergonomics of firefighting reviewed. Appl Ergon 41:161-172 . doi: 10.1016/j.apergo.2009.07.001

10. Havenith G (1999) Heat balance when wearing protective clothing. Ann Occup Hyg 43:289-296 . doi: 10.1093/annhyg/43.5.289

11. McLellan TM, Selkirk G a (2006) The management of heat stress for the firefighter: a review of work conducted on behalf of the Toronto Fire Service. Ind Health 44:414-426 . doi: 10.2486/indhealth.44.414

12. Lu Y, Song G, Li J (2013) Analysing performance of protective clothing upon hot liquid exposure using instrumented spray manikin. Ann Occup Hyg 57:793-804 . doi: 10.1093/annhyg/mes109

13. Holmér I, Kuklane K, Gao C (2006) Test of firefighter's turnout gear in hot and 
humid air exposure. Int J Occup Saf Ergon 12:297-305 . doi:

$10.1080 / 10803548.2006 .11076689$

14. Nunneley SA (1989) heat stress inprotective clothing . Interactions among physical and physiological factors . ScandJ Work EnvironHealth 15 Suppl $1: 52-57$

15. Havenith G, Heus R (2004) A test battery related to ergonomics of protective clothing. Appl Ergon 35:3-20 . doi: 10.1016/j.apergo.2003.11.001

16. Song G, Cao W, Gholamreza F (2011) Analyzing stored thermal energy and thermal protective performance of clothing. Text Res J. doi:

$10.1177 / 0040517511398943$

17. Scott RA (2005) Textiles for Protection. Woodhead publishing LTD

18. McLellan TM, Selkirk G a (2004) Heat stress while wearing long pants or shorts under firefighting protective clothing. Ergonomics 47:75-90 . doi: $10.1080 / 00140130310001611125$

19. (2015) ISO 11999-3, PPE for firefighters-Test methods and requirements for PPE used by firefighters who are at risk of exposure to high levels of heat and/or flame while fighting fires occurring in structures-Part 3: Clothing, International Sandard Orgnization G

20. (2013) NFPA 1971,Protective Ensembles for Structural Fire Fighting and Protximity Fire Fighting, National Fire Protection Association, Quincy, MA .

21. (2014) EN 469, Protective Clothing for Fire-Fighters - Performance requirements for protective clothing for firefighting,European Standard, 
Brussels

22. Jin L, Park PK, Hong KA, Yoon KJ (2015) Effect of Aluminized Fabrics on Radiant Protective Performance of Fire Proximity Suit Materials. Ann Occup Hyg 59:243-252 . doi: 10.1093/annhyg/meu081

23. Keiser C (2007) Steam Burns Moisture Management in Firefighter Protective Clothing. Swiss Federal Institute of Technology, ETH Zurich

24. Atalay O, Bahadir SK, Kalaoglu F (2015) An Analysis on the Moisture and Thermal Protective Performance of Firefighter Clothing Based on Different Layer Combinations and Effect of Washing on Heat Protection and Vapour Transfer Performance. Adv Mater Sci Eng 2015: . doi: 10.1155/2015/540394

25. (2003) ISO 17492, Clothing for protection against heat and flame-Determination of heat transmission on exposure to both flame and radiant heat,International Standard Orgnization,Geneva

26. (1993) ISO 11092,Textiles-Physiological effects-Measurement of thermal and water-vapour resistance under steady-state conditions (sweating guarded-hotplate test), International Standard Orgnization, Geneva

27. (2014) ASTM 1868,Standard Test Method for Thermal and Evaporative Resistance of Clothing Materials Using a Sweating Hot Plate, American Society of Testing Materials, West Conshohocken, PA

28. Stoll AM, Chianta MA (1969) Method and rating system for evaluation of thermal protection. Aerosp Med 40:1232-1238

29. Torvi DA, Dale JD (1999) Heat transfer in thin fibrous materials under high 
heat flux. Fire Technol 35:210-231 . doi: 10.1023/A:1015484426361

30. Torvi DA, Threlfall TG (2006) Heat transfer model of flame resistant fabrics during cooling after exposure to fire. Fire Technol 42:27-48 . doi:

$10.1007 / \mathrm{s} 10694-005-3733-8$

31. Guowen Song, Paskaluk S, Sati R, et al (2011) Thermal protective performance of protective clothing used for low radiant heat protection. Text Res J 81:311323 . doi: 10.1177/0040517510380108

32. Holmer I (1985) Heat Exchange and Thermal Insulation Compared in Woolen and Nylon Garments During Wear Trials. Text Res J 55:511-518 . doi: $10.1177 / 004051758505500901$

33. Frackiewicz-Kaczmarek J, Psikuta A, Bueno M-A, Rossi RM (2015) Air gap thickness and contact area in undershirts with various moisture contents: influence of garment fit, fabric structure and fiber composition. Text Res J 85: . doi: $10.1177 / 0040517514551458$

34. Psikuta A, Frackiewicz-Kaczmarek J, Frydrych I, Rossi R (2012) Quantitative evaluation of air gap thickness and contact area between body and garment. Text Res J 82:1405-1413 . doi: 10.1177/0040517512436823

35. McLellan TM, Havenith G (2016) Protective clothing ensembles and physical employment standards ${ }^{1}$. Appl Physiol Nutr Metab 41:S121-S130 . doi:

10.1139/apnm-2015-0474

36. Congalton D (1999) Shape Memory Alloys For Use in Thermally Activated Clothing, Protection Against Flame and Heat. FIRE Mater 23:223-226 
37. Zhang G, Zhang X, Huang H, et al (2016) Toward Wearable Cooling Devices : Highly Flexible Electrocaloric Ba0.67Sr0.33TiO3 Nanowire Arrays. Adv Mater 0-31 . doi: 10.1002/adma.201506118

38. McLellan TM, Havenith G (2016) Protective clothing ensembles and physical employment standards ${ }^{1}$. Appl Physiol Nutr Metab 41:S121-S130 . doi: 10.1139/apnm-2015-0474

39. Malchaire J, Piette A, Kampmann B, et al (2001) Development and validation of the predicted heat strain model. Ann Occup Hyg 45:123-135 . doi: 10.1093/annhyg/45.2.123

40. Griefahn B, Kunemund C, Brode P (2003) Evaluation of performance and load in simulated rescue tasks for a novel design SCBA: Effect of weight, volume and weight distribution. Appl Ergon 34:157-165 . doi: $10.1016 / \mathrm{S} 0003-6870(02) 00143-6$

41. Parsons K (2006) Heat stress standard ISO 7243 and its global application. Ind Health 44:368-379 . doi: 10.2486/indhealth.44.368

42. Jayalakshmi T, Santhakumaran A (2011) Statistical Normalization and Backpropagation for Classification. Int J Comput Theory Eng 3:89-93

43. Jayalakshmi T, Santhakumaran A (2011) Statistical Normalization and Backpropagation for Classification. Int J Comput Theory Eng 3:89-93

44. Liao X, Li Y, Hu J, et al (2016) Psychophysical Relations between Interacted Fabric Thermal-Tactile Properties and Psychological Touch Perceptions. J Sens Stud 31:181-192 . doi: 10.1111/joss.12189 
45. Fahy RF, LeBlanc PR, Molis JL (2016) Firefighter fatalities in the United States. Report 
Table 1. Detailed information of the five different types of firefighter protective

clothing assemblies

\begin{tabular}{|c|c|c|c|c|c|c|c|}
\hline $\begin{array}{c}\text { Assembly } \\
\text { code }\end{array}$ & Layers & \begin{tabular}{|c|} 
Code of \\
layer
\end{tabular} & Component \& Discription & Fabric structure & $\begin{array}{l}\text { Weight } \\
\left(\omega, \mathrm{g} / \mathrm{m}^{2}\right)\end{array}$ & $\begin{array}{c}\text { Thickness } \\
(\delta, \mathrm{mm})\end{array}$ & Image \\
\hline \multirow{4}{*}{ A } & $\begin{array}{l}\text { Outer } \\
\text { layer }\end{array}$ & $\mathrm{O}_{1}$ & $100 \%$ meta-aramid (black) & $\begin{array}{l}\text { plain woven } \\
\text { (ripstop) }\end{array}$ & $251.7 \pm 2.7$ & $0.51 \pm 0.01$ & \\
\hline & \begin{tabular}{|c|}
$\begin{array}{c}\text { Moisture } \\
\text { barrier }\end{array}$ \\
\end{tabular} & $\mathrm{M}_{1}$ & $\begin{array}{l}\text { 90\% meta-aramid blended } 10 \% \text { para-aramid } \\
\text { nonwoven coated with PTFE* membrane }\end{array}$ & $\begin{array}{c}\text { nonwoven, } \\
\text { membrane }\end{array}$ & $144.7 \pm 2.0$ & $0.91 \pm 0.01$ & \\
\hline & \begin{tabular}{|c|}
$\begin{array}{c}\text { Thermal } \\
\text { barrier }\end{array}$ \\
\end{tabular} & $\mathrm{T}_{1}$ & $100 \%$ meta-aramid & woven & $150.7 \pm 3.8$ & $0.41 \pm 0.02$ & \\
\hline & \multicolumn{4}{|c|}{ Total } & $547.0 \pm 3.6$ & $1.83 \pm 0.02$ & \\
\hline \multirow{4}{*}{ B } & $\begin{array}{l}\text { Outer } \\
\text { layer }\end{array}$ & $\mathrm{O}_{2}$ & $40 \% \mathrm{PBI}^{*}$ blended $60 \%$ para-aramid (gold) & $\begin{array}{c}\text { plain woven } \\
\text { (ripstop) }\end{array}$ & $253.3 \pm 3.1$ & $0.51 \pm 0.01$ & \\
\hline & \begin{tabular}{|c|}
$\begin{array}{c}\text { Moisture } \\
\text { barrier }\end{array}$ \\
\end{tabular} & $\mathrm{M}_{1}$ & $\begin{array}{l}\text { 90\% meta-aramid blended } 10 \% \text { para-aramid } \\
\text { nonwoven coated with PTFE* membrane }\end{array}$ & $\begin{array}{c}\text { nonwoven, } \\
\text { membrane }\end{array}$ & $144.7 \pm 2.0$ & $0.91 \pm 0.01$ & \\
\hline & \begin{tabular}{|c|}
$\begin{array}{c}\text { Thermal } \\
\text { barrier }\end{array}$ \\
\end{tabular} & $\mathrm{T}_{1}$ & $100 \%$ meta-aramid & woven & $150.7 \pm 3.8$ & $0.41 \pm 0.02$ & \\
\hline & \multicolumn{4}{|c|}{ Total } & $548.7 \pm 8.7$ & $1.83 \pm 0.02$ & \\
\hline \multirow{4}{*}{$\mathrm{B}_{1}$} & $\begin{array}{l}\text { Outer } \\
\text { layer }\end{array}$ & $\mathrm{O}_{2}$ & $40 \%$ PBI$^{*}$ blended $60 \%$ para-aramid (gold) & $\begin{array}{l}\text { plain woven } \\
\text { (ripstop) }\end{array}$ & $253.3 \pm 3.1$ & $0.51 \pm 0.01$ & \\
\hline & \begin{tabular}{|c|}
$\begin{array}{c}\text { Moisture } \\
\text { barrier }\end{array}$ \\
\end{tabular} & $\mathrm{M}_{2}$ & $\begin{array}{l}100 \% \text { meta-aramid coated with PTFE** } \\
\text { membrane }\end{array}$ & woven, membrane & $182.7 \pm 2.8$ & $0.35 \pm 0.01$ & \\
\hline & \begin{tabular}{|c|}
$\begin{array}{c}\text { Thermal } \\
\text { barrier }\end{array}$ \\
\end{tabular} & $\mathrm{T}_{2}$ & $\begin{array}{l}100 \% \text { meta-aramid nonwoven combined with } \\
100 \% \text { meta-aramid woven }\end{array}$ & nonwoven, woven & $311.0 \pm 5.0$ & $2.97 \pm 0.08$ & \\
\hline & \multicolumn{4}{|c|}{ Total } & $747.0 \pm 6.7$ & $3.83 \pm 0.08$ & \\
\hline \multirow{4}{*}{$\mathrm{B}_{2}$} & $\begin{array}{l}\text { Outer } \\
\text { layer }\end{array}$ & $\mathrm{O}_{2}$ & 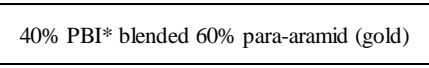 & $\begin{array}{l}\text { plain woven } \\
\text { (ripstop) }\end{array}$ & $253.3 \pm 3.1$ & $0.51 \pm 0.01$ & \\
\hline & \begin{tabular}{|c|}
$\begin{array}{c}\text { Moisture } \\
\text { barrier }\end{array}$ \\
\end{tabular} & $\mathrm{M}_{2}$ & $\begin{array}{l}100 \% \text { meta-aramid coated with PTFE* } \\
\text { membrane }\end{array}$ & woven, membrane & $182.7 \pm 2.8$ & $0.35 \pm 0.01$ & \\
\hline & \begin{tabular}{|c|}
$\begin{array}{c}\text { Thermal } \\
\text { barrier }\end{array}$ \\
\end{tabular} & $\mathrm{T}_{3}$ & $\begin{array}{l}100 \% \text { meta-aramid nonwoven combined with } \\
100 \% \text { meta-aramid woven }\end{array}$ & nonwoven, woven & $351.0 \pm 9.2$ & $3.93 \pm 0.06$ & \\
\hline & \multicolumn{4}{|c|}{ Total } & $787.0 \pm 9.4$ & $4.78 \pm 0.06$ & \\
\hline \multirow{4}{*}{$\mathrm{C}$} & $\begin{array}{l}\text { Outer } \\
\text { layer }\end{array}$ & $\mathrm{O}_{3}$ & $40 \%$ PBO* blended $60 \%$ para-aramid (gold) & $\begin{array}{l}\text { plain woven } \\
\text { (ripstop) }\end{array}$ & $193.0 \pm 2.1$ & $0.37 \pm 0.01$ & \\
\hline & \begin{tabular}{|c|}
$\begin{array}{c}\text { Moisture } \\
\text { barrier }\end{array}$ \\
\end{tabular} & $\mathrm{M}_{2}$ & $\begin{array}{l}100 \% \text { meta-aramid coated with PTFE* } \\
\text { membrane }\end{array}$ & woven, membrane & $182.7 \pm 2.8$ & $0.35 \pm 0.01$ & \\
\hline & \begin{tabular}{|c|}
$\begin{array}{c}\text { Thermal } \\
\text { barrier }\end{array}$ \\
\end{tabular} & $\mathrm{T}_{2}$ & $\begin{array}{l}100 \% \text { meta-aramid nonwoven combined with } \\
100 \% \text { meta-aramid woven }\end{array}$ & nonwoven, woven & $311.0 \pm 5.0$ & $2.97 \pm 0.08$ & \\
\hline & \multicolumn{4}{|c|}{ Total } & $686.7 \pm 4.1$ & $3.70 \pm 0.08$ & \\
\hline
\end{tabular}


Table 2. International standards of performance tests of thermal protection and anti-heat stress for firefighter protective clothing

\begin{tabular}{|c|c|c|c|c|c|c|c|c|}
\hline Standard & \multicolumn{4}{|c|}{ Thermal protection test } & \multicolumn{4}{|c|}{ Anti-heat stress test } \\
\hline \multirow{7}{*}{$\begin{array}{c}\text { ISO } 11999-3 \\
: 2015\end{array}$} & \multirow{2}{*}{ Test method } & \multirow{2}{*}{ Index } & \multicolumn{2}{|c|}{ Performance level } & \multirow{2}{*}{ Test method } & \multirow{2}{*}{ Index } & \multicolumn{2}{|c|}{ Performance level } \\
\hline & & & A1 & $\mathrm{A} 2$ & & & $\mathrm{~d}_{1}$ & $\mathrm{~d}_{2}$ \\
\hline & \multirow{2}{*}{ ISO 9151} & $\mathrm{HTI}_{24}(\mathrm{~s})$ & $\geqslant 13$ & $\geqslant 17$ & \multirow{2}{*}{ ISO 11092} & \multirow{2}{*}{$\mathrm{WVR}\left(\mathrm{m}^{2} \mathrm{~Pa} / \mathrm{W}\right)$} & \multirow{2}{*}{$\leqslant 40$} & \multirow{2}{*}{$\leqslant 30$} \\
\hline & & $\mathrm{HTI}_{24}-\mathrm{HTI}_{12}(\mathrm{~s})$ & $\geqslant 4$ & $\geqslant 6$ & & & & \\
\hline & \multirow{2}{*}{$\begin{array}{c}\text { ISO } 6942 \\
\text { (Mehtod B) }\end{array}$} & $\mathrm{RHTI}_{24}(\mathrm{~s})$ & $\geqslant 18$ & $\geqslant 26$ & \multirow{3}{*}{$\begin{array}{c}\text { ASTM F } 1868 \\
\text { (Part C) }\end{array}$} & \multirow{3}{*}{ THL $\left(\mathrm{W} / \mathrm{m}^{2}\right)$} & \multirow{3}{*}{$\geqslant 200$} & \multirow{3}{*}{$\geqslant 300$} \\
\hline & & $\mathrm{RHTI}_{24}-\mathrm{HTI}_{12}(\mathrm{~s})$ & $\geqslant 4$ & $\geqslant 8$ & & & & \\
\hline & ISO 17492 & TTI $\left(\mathrm{J} / \mathrm{m}^{2}\right)$ & $\geqslant 1050$ & $\geqslant 1400$ & & & & \\
\hline \multirow{2}{*}{$\begin{array}{c}\text { NFPA } 1971 \\
: 2013\end{array}$} & Test method & Index & \multicolumn{2}{|c|}{ Requirement } & Test method & Index & \multicolumn{2}{|c|}{ Requirement } \\
\hline & ASTM F2700 & TPP rating $\left(\mathrm{cal} / \mathrm{cm}^{2}\right)$ & \multicolumn{2}{|c|}{$\geqslant 35$} & $\begin{array}{c}\text { ASTM F } 1868 \\
\text { (Part C) }\end{array}$ & THL (W/m²) & \multicolumn{2}{|c|}{ N/A } \\
\hline \multirow{6}{*}{ EN $469: 2014$} & \multirow{2}{*}{ Test method } & \multirow{2}{*}{ Index } & \multicolumn{2}{|c|}{ Performance level } & \multirow{2}{*}{ Test method } & \multirow{2}{*}{ Index } & \multicolumn{2}{|c|}{ Performance level } \\
\hline & & & $\mathrm{X} 1$ & $\mathrm{X} 2$ & & & $\mathrm{Z1}$ & $\mathrm{Z2}$ \\
\hline & \multirow{2}{*}{ EN 367} & $\mathrm{HTI}_{24}(\mathrm{~s})$ & $\geqslant 9$ & $\geqslant 13$ & \multirow{4}{*}{ N 31092} & \multirow{4}{*}{ WVR $\left(\mathrm{m}^{2} \mathrm{~Pa} / \mathrm{W}\right)$} & \multirow{4}{*}{$30-45$} & \multirow{4}{*}{$\leqslant 30$} \\
\hline & & $\mathrm{HTI}_{24}-\mathrm{HTI}_{12}(\mathrm{~s})$ & $\geqslant 3$ & $\geqslant 4$ & & & & \\
\hline & \multirow{2}{*}{$\begin{array}{c}\text { EN ISO } 6942 \\
\text { (Mehtod B) }\end{array}$} & $\mathrm{RHTI}_{24}(\mathrm{~s})$ & $\geqslant 10$ & $\geqslant 18$ & & & & \\
\hline & & $\mathrm{RHTI}_{24}-\mathrm{HTI}_{12}$ (s) & $\geqslant 3$ & $\geqslant 4$ & & & & \\
\hline
\end{tabular}


Table 3. Flame protective performance of firefighter protective clothing assemblies

\begin{tabular}{|c|c|c|c|c|c|}
\hline $\begin{array}{c}\text { Assembly } \\
\text { code }\end{array}$ & $\mathrm{t}_{2 \mathrm{Burn}}(\mathrm{sec}$.) & $\mathrm{HTI}_{12}(\mathrm{sec})$. & $\mathrm{HTI}_{24}(\mathrm{sec})$. & $\mathrm{HTI}_{24}-\mathrm{HTI}_{12}(\mathrm{sec})$. & $\begin{array}{c}\text { Performance } \\
\text { level in ISO } \\
11999-3: 2015\end{array}$ \\
\hline $\mathrm{A}$ & $12.4 \pm 0.3$ & $9.5 \pm 0.1$ & $14.7 \pm 0.3$ & $5.2 \pm 0.1$ & $\mathrm{~A} 1$ \\
\hline $\mathrm{B}$ & $11.3 \pm 0.2$ & $9.1 \pm 0.2$ & $13.2 \pm 0.2$ & $4.2 \pm 0.1$ & $\mathrm{~A} 1$ \\
\hline $\mathrm{B}_{1}$ & $22.8 \pm 0.4$ & $17.0 \pm 0.3$ & $23.9 \pm 0.4$ & $6.8 \pm 0.3$ & $\mathrm{~A} 2$ \\
\hline $\mathrm{B}_{2}$ & $26.9 \pm 0.7$ & $19.0 \pm 0.4$ & $27.5 \pm 0.6$ & $8.5 \pm 0.3$ & $\mathrm{~A} 2$ \\
\hline $\mathrm{C}$ & $21.5 \pm 0.7$ & $15.8 \pm 0.4$ & $22.8 \pm 0.6$ & $7.1 \pm 0.3$ & $\mathrm{~A} 2$ \\
\hline
\end{tabular}

Table 4. Radiant protective performance of firefighter protective clothing assemblies

\begin{tabular}{|c|c|c|c|c|}
\hline $\begin{array}{c}\text { Assembly } \\
\text { code }\end{array}$ & RHTI $_{12}(\mathrm{sec})$. & RHTI $_{24}(\mathrm{sec})$. & RHTI $_{24}-\mathrm{RHTI}_{12}(\mathrm{sec})$. & $\begin{array}{c}\text { Performance } \\
\text { level in ISO } \\
11999-3: 2015\end{array}$ \\
\hline $\mathrm{A}$ & $9.9 \pm 0.2$ & $14.5 \pm 0.3$ & $4.6 \pm 0.1$ & fail \\
\hline $\mathrm{B}$ & $12.1 \pm 0.6$ & $18.0 \pm 0.8$ & $5.8 \pm 0.2$ & $\mathrm{~A} 1$ \\
\hline $\mathrm{B}_{1}$ & $21.4 \pm 0.3$ & $31.2 \pm 0.4$ & $9.8 \pm 0.2$ & $\mathrm{~A} 2$ \\
\hline $\mathrm{B}_{2}$ & $23.9 \pm 0.9$ & $35.4 \pm 1.6$ & $11.5 \pm 0.7$ & $\mathrm{~A} 2$ \\
\hline $\mathrm{C}$ & $20.4 \pm 0.8$ & $30.3 \pm 1.3$ & $9.9 \pm 0.5$ & $\mathrm{~A} 2$ \\
\hline
\end{tabular}

Table 5. Thermal protective performance of firefighter protective clothing assemblies

\begin{tabular}{|c|c|c|c|c|}
\hline $\begin{array}{c}\text { Assembly } \\
\text { code }\end{array}$ & $\mathrm{t}_{\text {2Burn }}(\mathrm{sec})$. & TPP rating $\left(\mathrm{cal} / \mathrm{cm}^{2}\right)$ & TTI $\left(\mathrm{J} / \mathrm{m}^{2}\right)$ & $\begin{array}{c}\text { Performance } \\
\text { level in ISO } \\
11999-3: 2015\end{array}$ \\
\hline $\mathrm{A}$ & $14.5 \pm 0.2$ & $28.7 \pm 0.5$ & $1201 \pm 21$ & A1 \\
\hline $\mathrm{B}$ & $13.6 \pm 0.4$ & $27.0 \pm 0.8$ & $1132 \pm 33$ & A1 \\
\hline $\mathrm{B}_{1}$ & $27.0 \pm 1.2$ & $51.8 \pm 2.5$ & $2170 \pm 106$ & A2 \\
\hline $\mathrm{B}_{2}$ & $30.0 \pm 0.9$ & $56.8 \pm 1.7$ & $2379 \pm 73$ & A2 \\
\hline $\mathrm{C}$ & $26.2 \pm 0.8$ & $51.1 \pm 1.5$ & $2143 \pm 63$ & A2 \\
\hline
\end{tabular}


Table 6. Performance of anti-heat stress for firefighter protective clothing assemblies

\begin{tabular}{|c|c|c|c|c|c|}
\hline $\begin{array}{c}\text { Assembly } \\
\text { code }\end{array}$ & TR $\left(\mathrm{m}^{2} \mathrm{~K} / \mathrm{W}\right)$ & $\begin{array}{c}\mathrm{WVR} \\
\left(\mathrm{m}^{2} \mathrm{~Pa} / \mathrm{W}\right)\end{array}$ & $\begin{array}{c}\text { Performance } \\
\text { level in ISO } \\
11999-3: 2015\end{array}$ & THL $\left(\mathrm{W} / \mathrm{m}^{2}\right)$ & $\begin{array}{c}\text { Performance } \\
\text { level in ISO } \\
11999-3: 2015\end{array}$ \\
\hline $\mathrm{A}$ & $0.054 \pm 0.001$ & $17.3 \pm 0.6$ & $\mathrm{~d}_{2}$ & $277.4 \pm 3.6$ & $\mathrm{~d}_{1}$ \\
\hline $\mathrm{B}$ & $0.064 \pm 0.002$ & $17.5 \pm 0.3$ & $\mathrm{~d}_{2}$ & $266.2 \pm 4.1$ & $\mathrm{~d}_{1}$ \\
\hline $\mathrm{B}_{1}$ & $0.158 \pm 0.003$ & $21.1 \pm 0.7$ & $\mathrm{~d}_{2}$ & $195.8 \pm 4.9$ & fail \\
\hline $\mathrm{B}_{2}$ & $0.192 \pm 0.010$ & $26.1 \pm 0.3$ & $\mathrm{~d}_{2}$ & $164.0 \pm 2.9$ & fail \\
\hline $\mathrm{C}$ & $0.164 \pm 0.010$ & $22.3 \pm 0.3$ & $\mathrm{~d}_{2}$ & $187.7 \pm 4.0$ & fail \\
\hline
\end{tabular}

Table 7. Essential values for calculations of $\mathrm{TP}_{\text {sum }}$ and $\mathrm{TP}_{\text {product }}$

\begin{tabular}{|c|c|c|c|c|c|c|c|c|}
\hline \multirow{2}{*}{$\begin{array}{c}\text { Assembly } \\
\text { Code }\end{array}$} & \multirow{2}{*}{ TTI } & \multirow{2}{*}{$\frac{\mathrm{THL}}{\delta \times \mathrm{w}}$} & \multirow{2}{*}{$(T T I)_{n}{ }^{*}$} & \multirow{2}{*}{$\left(\frac{T H L}{\delta \times w}\right) n^{*}$} & \multicolumn{3}{|c|}{$T P_{\text {sum }}=\alpha \times(T T I)_{n}+\beta \times\left(\frac{T H L}{\delta \times w}\right)_{n}$} & \multirow{2}{*}{$\begin{array}{l}T P_{\text {product }} \\
=T T I \times\left(\frac{T H L}{\delta \times w}\right)\end{array}$} \\
\hline & & & & & $\begin{array}{l}\alpha=0.05 \\
\beta=0.95\end{array}$ & $\begin{array}{l}\alpha=0.07 \\
\beta=0.93\end{array}$ & $\begin{array}{l}\alpha=0.20 \\
\beta=0.80\end{array}$ & \\
\hline A & 1201 & 0.277 & 0.06 & 1.00 & 0.95 & 0.93 & 0.80 & 333 \\
\hline B & 1132 & 0.252 & 0.00 & 0.95 & 0.90 & 0.88 & 0.76 & 300 \\
\hline $\mathrm{B}_{1}$ & 2170 & 0.069 & 0.83 & 0.11 & 0.14 & 0.16 & 0.25 & 149 \\
\hline $\mathrm{B}_{2}$ & 2379 & 0.044 & 1.00 & 0.00 & 0.05 & 0.07 & 0.20 & 104 \\
\hline $\mathrm{C}$ & 2143 & 0.074 & 0.81 & 0.13 & 0.16 & 0.18 & 0.27 & 159 \\
\hline
\end{tabular}

$*(T T I)_{n}$ is the normalized TTI value and $\left(\frac{T H L}{\delta \times w}\right)_{n}$ is the normalized $\frac{T H L}{\delta \times w}$ value. 


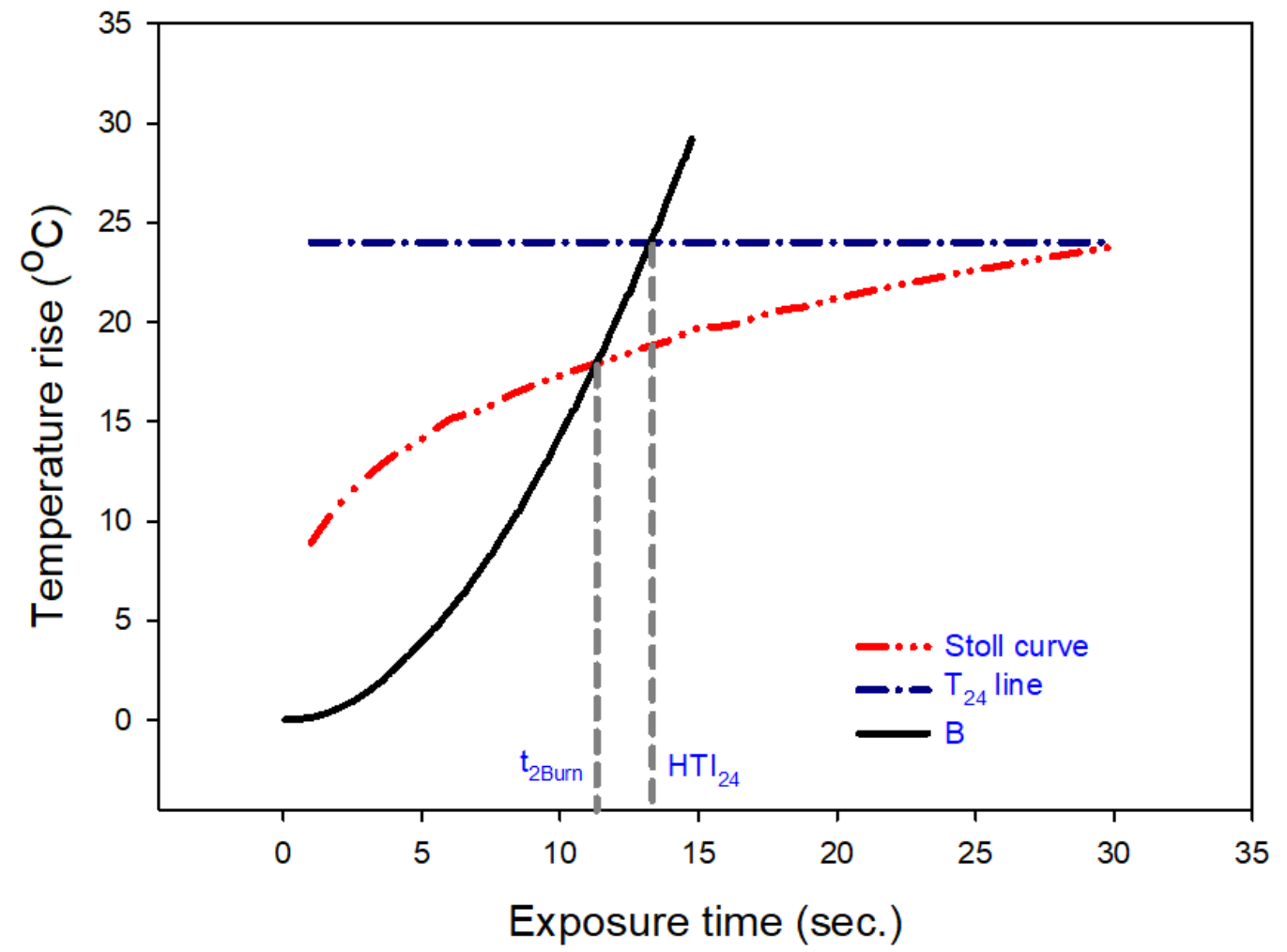

Figure 1. Determination of $\mathrm{t}_{2 \mathrm{Burn}}$ and $\mathrm{HTI}_{24}$ using B sample as an example in the FPP test. The point of intersection between the stoll curve and the B sample curve is $t_{2 B u r n}$. The point of intersection between $\mathrm{T}_{24}$ line and $\mathrm{B}$ curve is $\mathrm{HTI}_{24}$. 


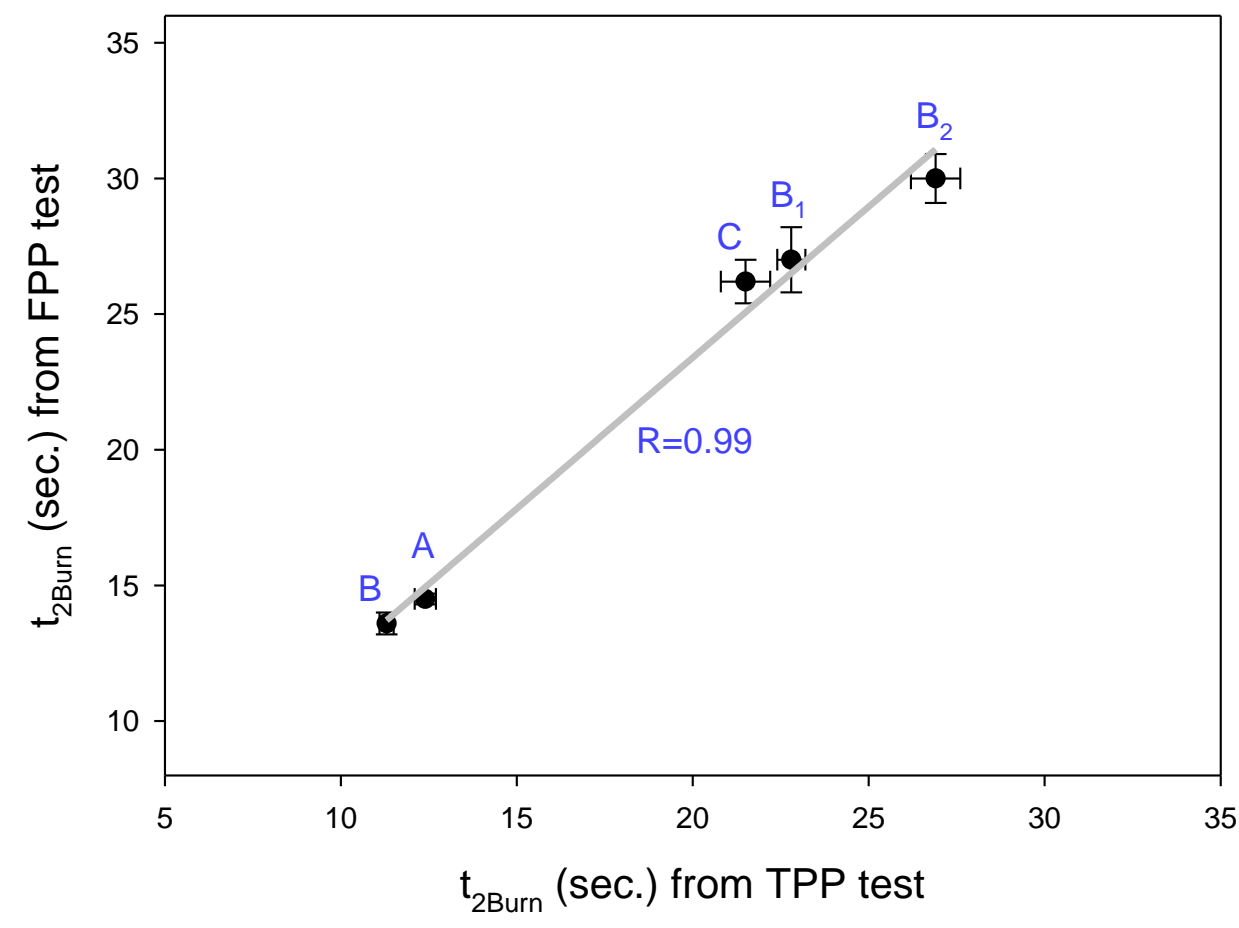

Figure 2. Linear relationship of the $t_{2}$ Burn values obtained in the FPP test and those in the TPP test. 

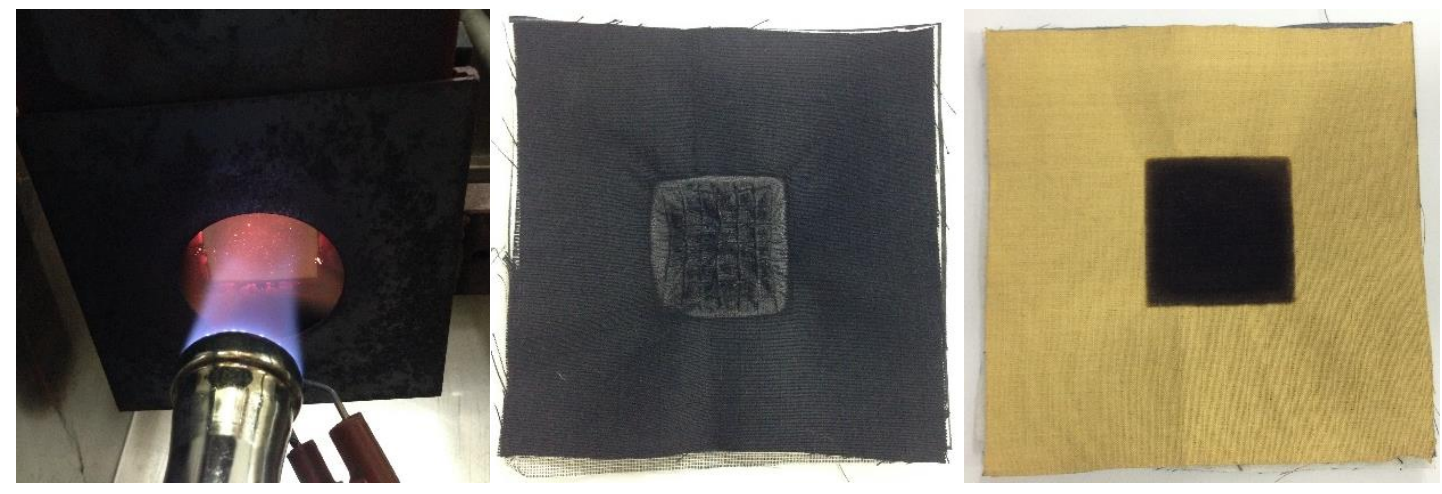

(a) FPP test

(b) A after FPP test

(c) B after FPP test
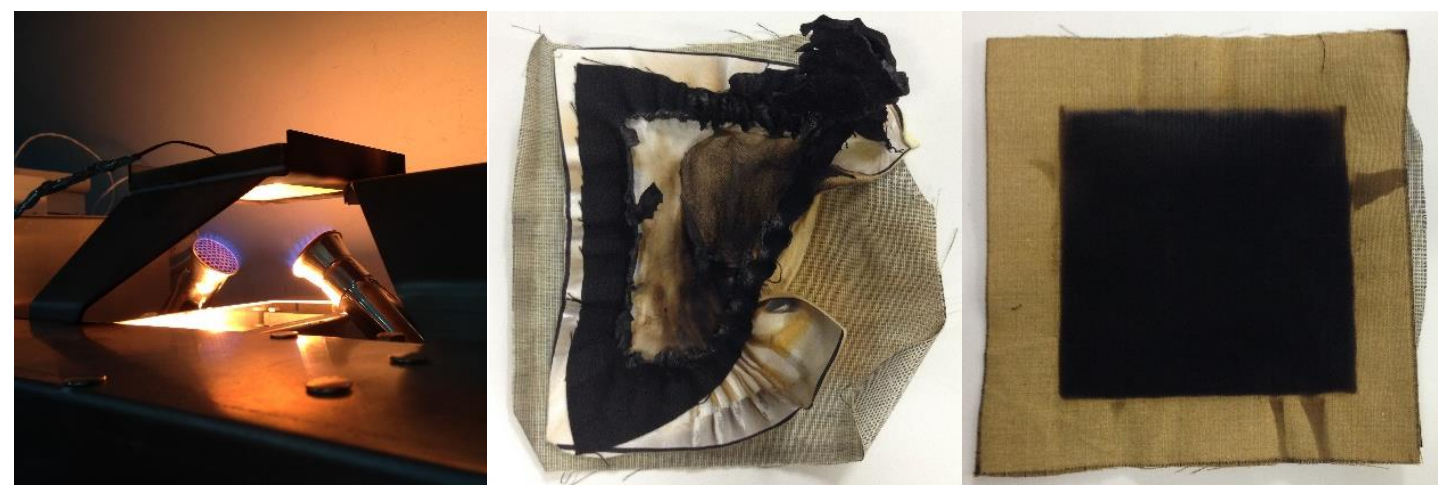

(d) TPP test

(e) A after TPP test

(f) B after TPP test

Figure 3. Damage of A and B samples after flame protective performance test and thermal protective performance test. 


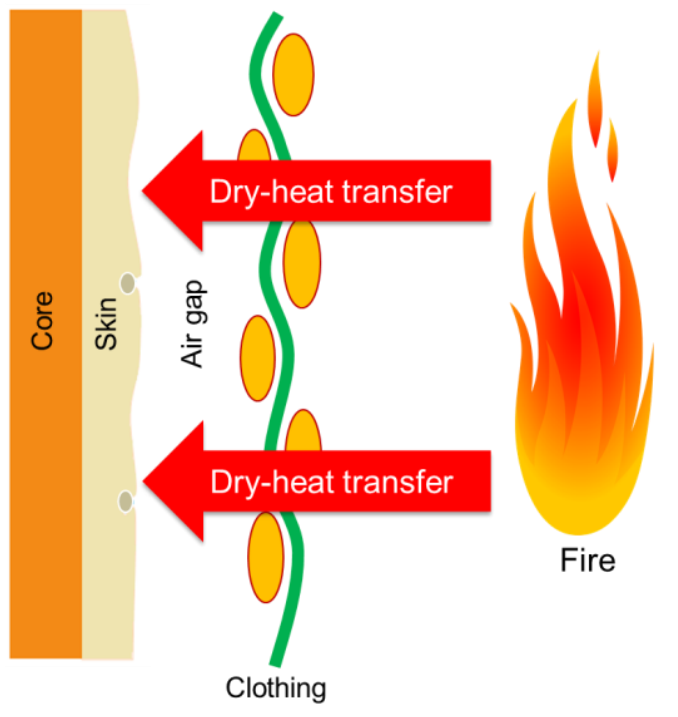

(a) Heat exchange process for thermal protection

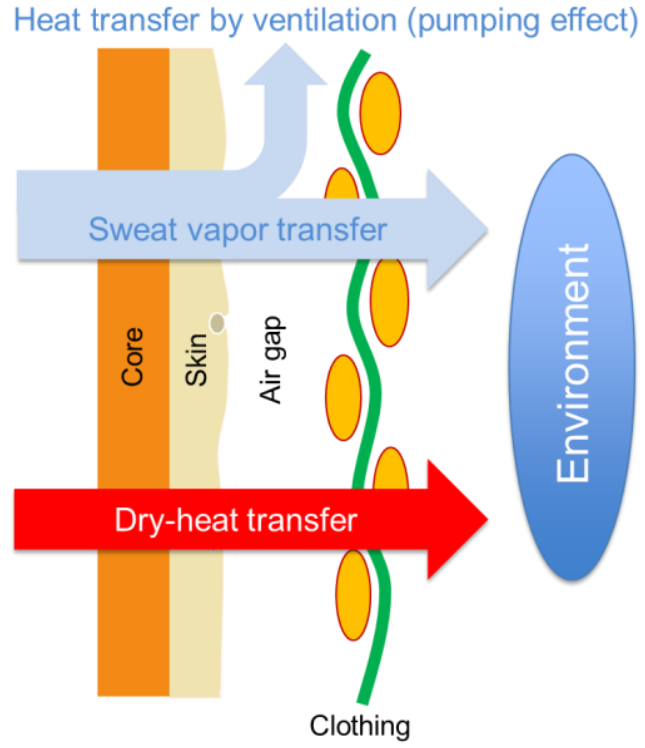

(b) Heat exchange process for heat stress

Figure 4. Diagrams for description and comparison of the ways of heat transfer within the processes of between (a) thermal protection and (b) heat stress. 


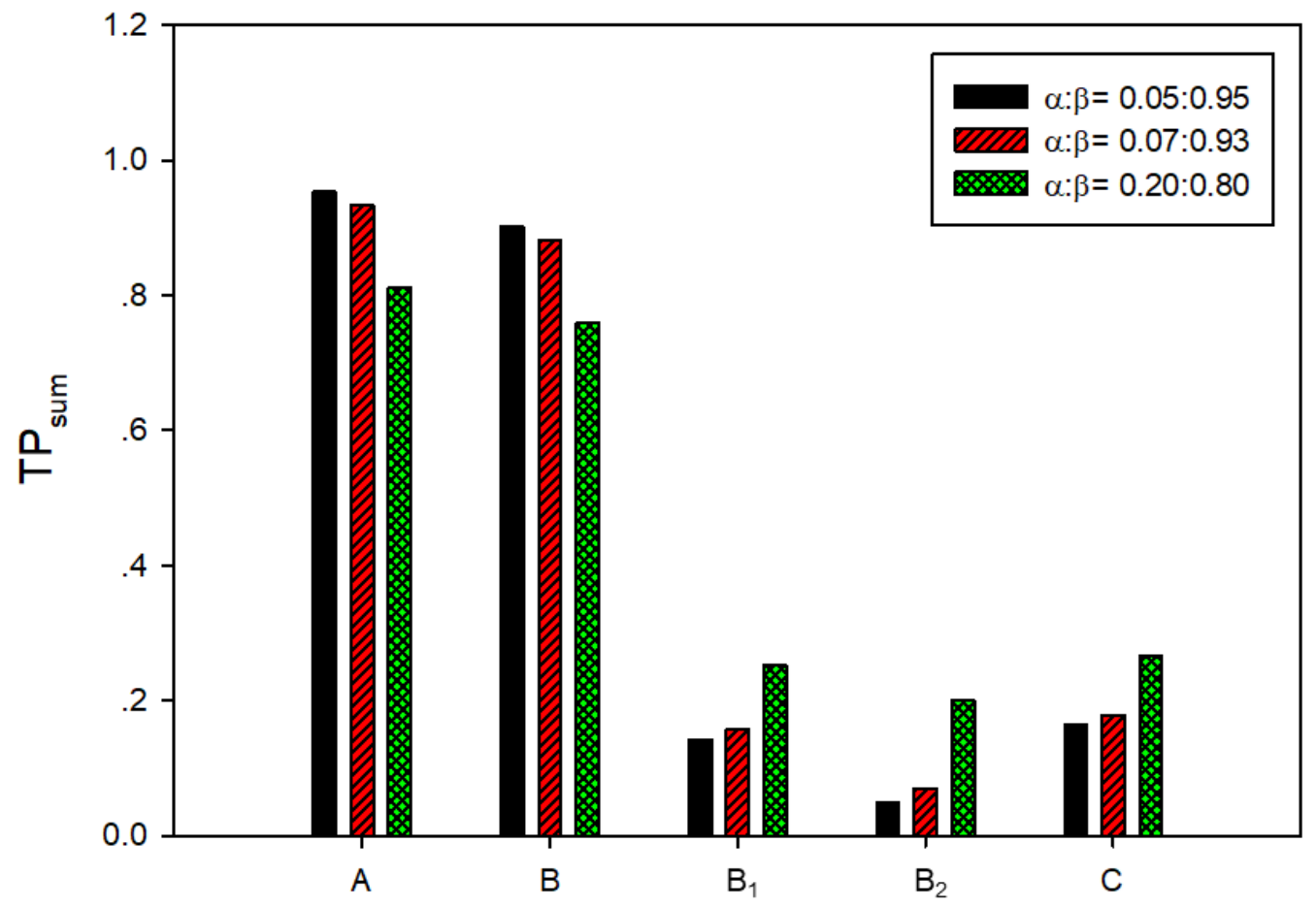

Firefighter Protective Clothing Assembly

Figure 5. $\mathrm{TP}_{\text {sum }}$ values for the firefighter protective clothing assemblies at various weighting values. 


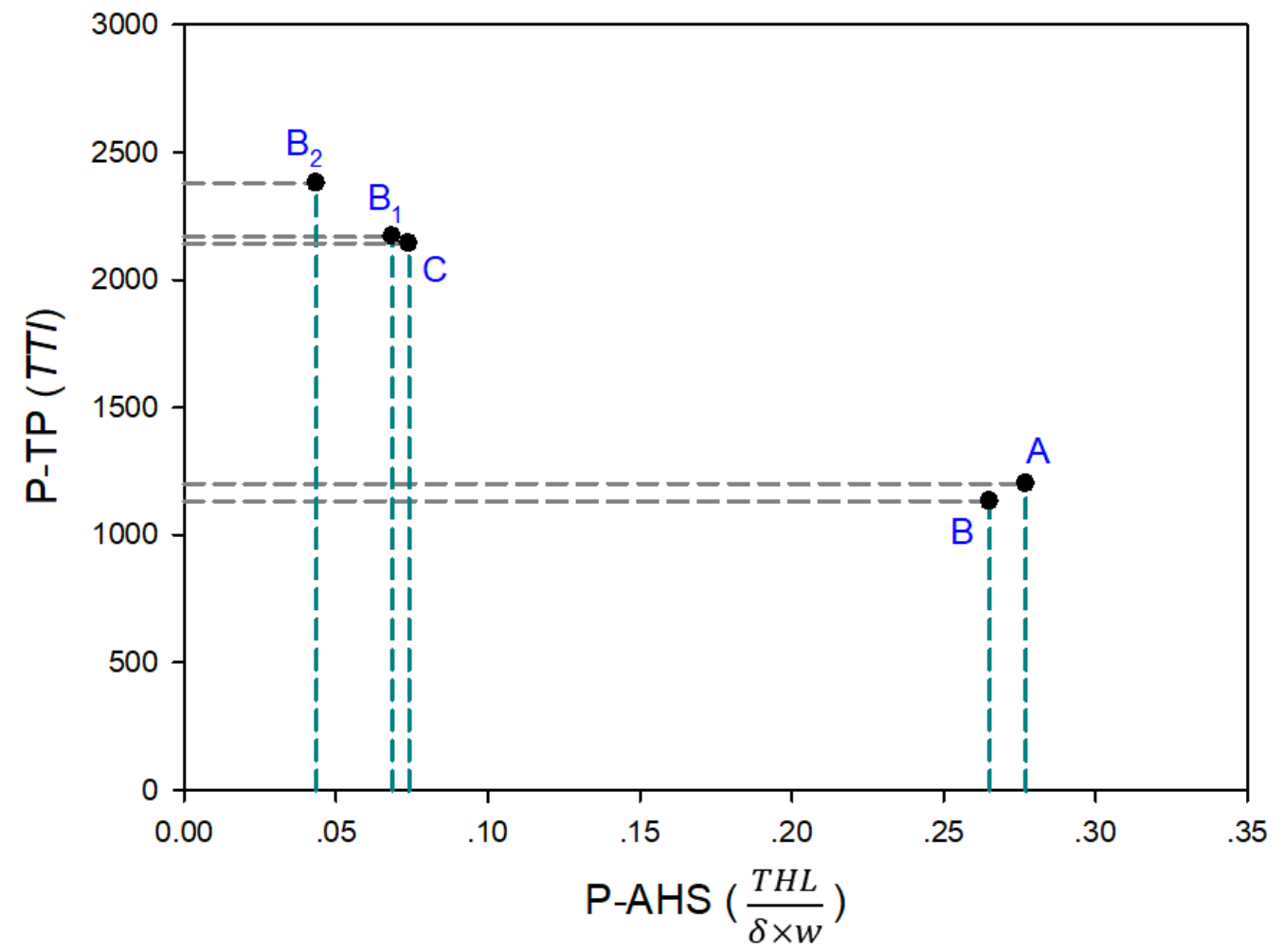

Figure 6. Rectangles representing the product of P-TP (TTI obtained from the TPP test) and P-AHS $\left(\frac{T H L}{\delta \times w}\right)$ for the five firefighter protective clothing assemblies. 


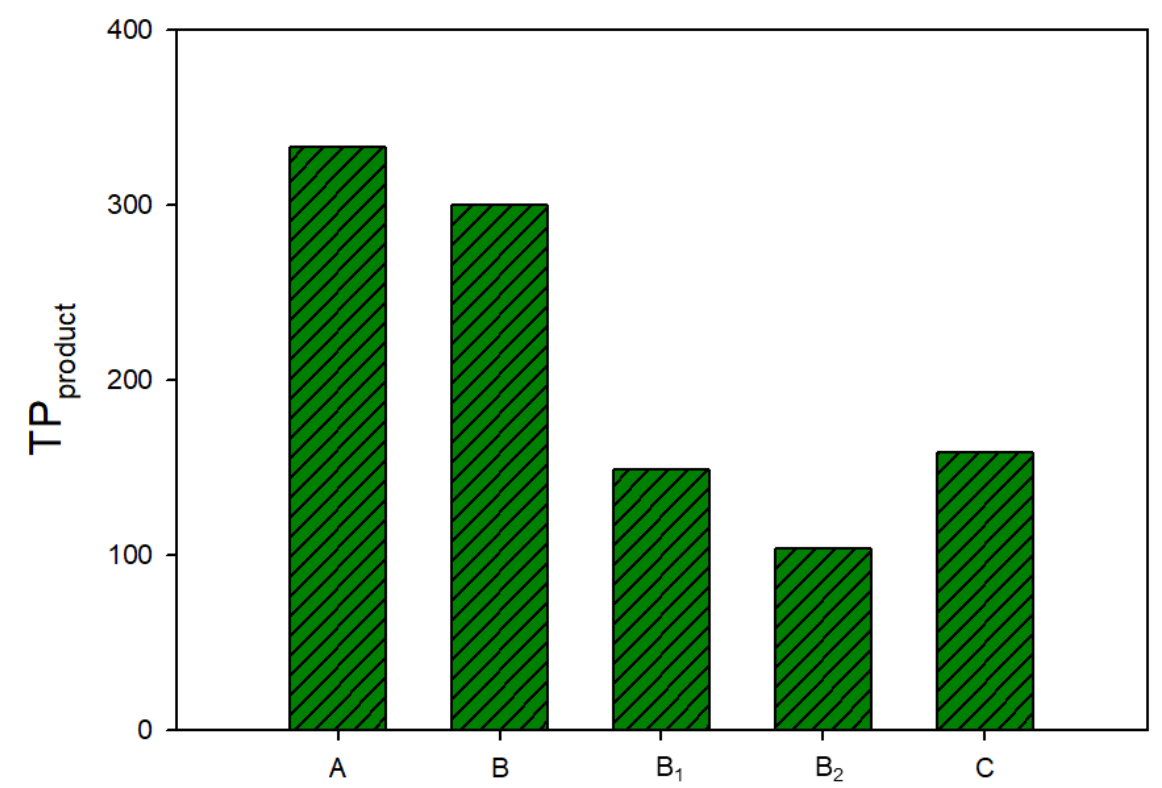

Firefighter Protective Clothing Assembly

Figure 7. $\mathrm{TP}_{\text {product }}$ values (areas of rectangles in Figure 6) for the firefighter protective clothing assemblies. 


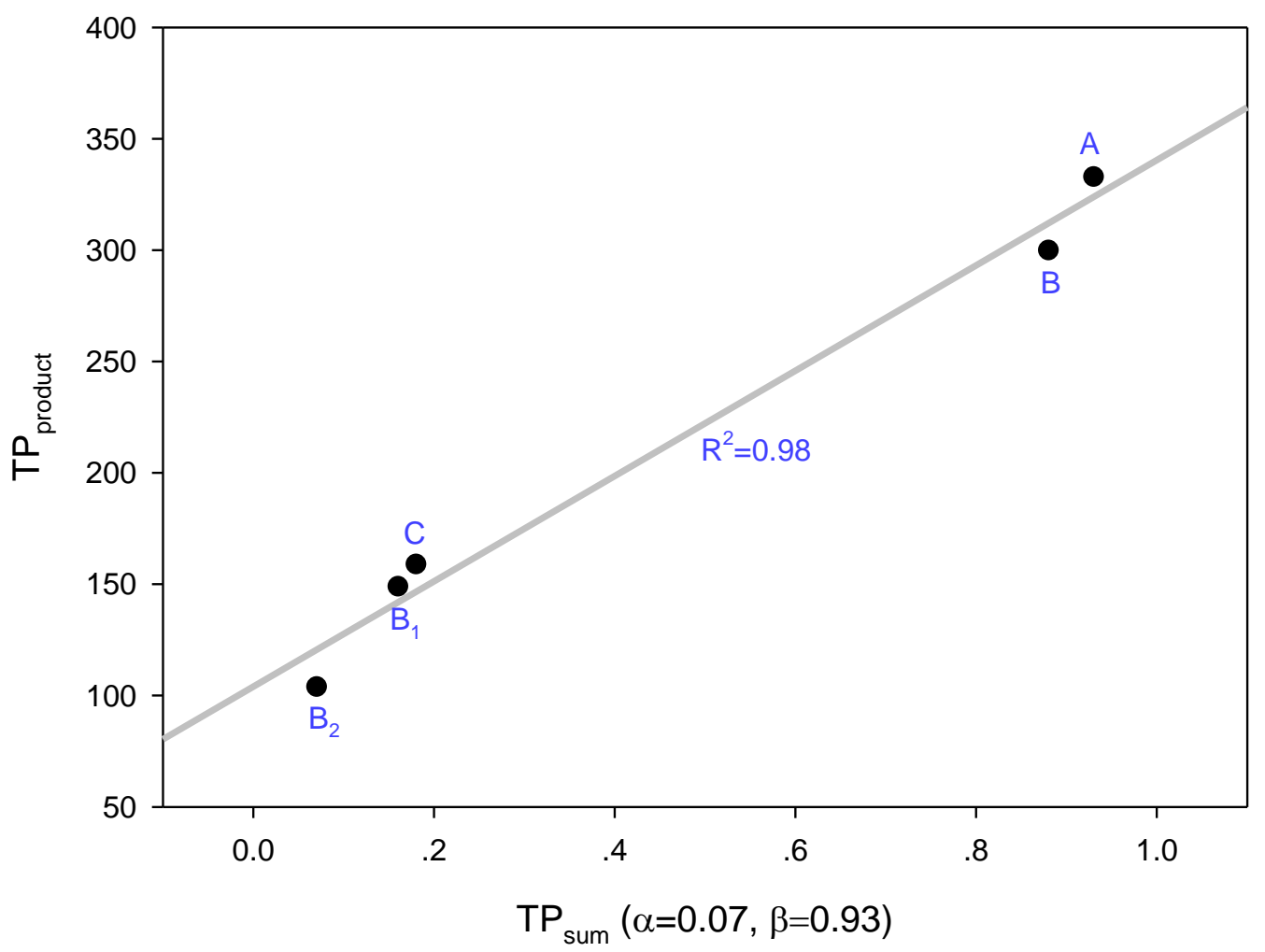

Figure 8. Relationship between $\mathrm{TP}_{\text {proudct }}$ and $\mathrm{TP}_{\text {sum }}(\alpha=0.07$ and $\beta=0.93)$ for five firefighter protective clothing assemblies. . 